\title{
Publication List of Prof. Dr. Ivar Karl Ugi
}

\section{Chronological:}

1. R. Huisgen, W. Rapp, I. Ugi, H. Walz, E. Mergenthaler

"Mittlere Ringe II. Sterische Hinderung der Mesomerie in 1,2-Benzocyclen-3-onen und verwandten Verbindungen"

Liebigs Ann. Chem. 586, 1-29 (1954)

2. R. Huisgen, I. Ugi, H. Brade, E. Rauenbusch

"Mittlere Ringe III. Eigenschaften und Reaktionen der 1,2-Benz-lactame"

Liebigs Ann. Chem. 586, 30-51 (1954)

3. R. Huisgen, W. Rapp, I. Ugi, H. Walz, I. Glogger

"Mittlere Ringe IV. Darstellung und Eigenschaften der 1,2,3,4-Benzocycla-1,3-dienone-(5)"

Liebigs Ann. Chem. 586, 52-69 (1954)

4. R. Huisgen, I. Ugi

"Zur Lösung eines klassischen Problems der organischen Stickstoff-Chemie"

Angew. Chem. 68, 705-706 (1956)

5. I. Ugi, R. Huisgen, K. Clusius, M. Vecchi

"Zur Reaktion des Benzol-diazonium-Ions mit Azid. Nachweis des Phenyl-pentazols als

Zwischenstufe"

Angew. Chem. 68, 753-754 (1956)

6. R. Huisgen, J. Witte, I. Ugi

"Zum Chemismus der Arylwanderung bei der Beckmann-Umlagerung, II"

Chem. Ber. 90, 1884-1849 (1957)

7. R. Huisgen, I. Ugi, E. Rauenbusch, V. Vossius, H. Oertel

"Mittlere Ringe IX. Weiteres zur sterischen Mesomeriehinderung in 1,2-Benzo-cyclen-(1)-onen-(3)"

Chem. Ber. 90, 1946-1959 (1957)

8. R. Huisgen, I. Ugi

"Pentazole I. Die Lösung eines klassichen Problems der organischen Stickstoffchemie"

Chem. Ber. 90, 2914-2927 (1957)

9. R. Huisgen, I. Ugi, M. T. Assemi, J. Witte

"Die Kinetik der Beckmann-Umlagerung der Cyclanon-Oxime"

Liebigs Ann. Chem. 602, 127-135 (1957)

10. R. Huisgen, I. Ugi

"Mittlere Ringe XI. Polycyclische Systeme mit Heteroatomen"

Liebigs Ann. Chem. 610, 57-66 (1957)

11. I. Ugi, R. Huisgen

"Pentazole II. Die Zerfallsgeschwindigkeit der Arylpentazole"

Chem. Ber. 91, 531-537 (1958)

12. I. Ugi, R. Meyr

"Neue Darstellungsmethode für Isonitrile"

Angew. Chem. 70, 702-703 (1958)

13. I. Ugi, H. Perlinger, L. Behringer

"Pentazole III. Kristallisierte Arylpentazole"

Chem. Ber. 91, 2324-2329 (1958)

14. I. Ugi, H. Perlinger, L. Behringer 
"Die Reduktion von Alkyl- und Arylaziden mit alkalischem Arsenit"

Chem. Ber. 91, 2330-2336 (1958)

15. I. Ugi, H. Perlinger, L. Behringer

"Pentazole IV. Der Konstitutionsbeweis für kristallisiertes [p-Aethoxy-phenyl]-pentazol"

Chem. Ber. 92, 1864-1866 (1959)

16. I. Ugi, R. Meyr, U. Fetzer, C. Steinbrückner

"Versuche mit Isonitrilen"

Angew. Chem. 71, 386 (1959)

17. R. Huisgen, E. Laschtuvka, I. Ugi, A. Kammermeier

"Syntheseversuche in der Oxepin- und Azepin-Reihe"

Liebigs Ann. Chem. 630, 128-139 (1960)

18. I. Ugi, C. Steinbrückner

"Über ein neues Kondensations-Prinzip"

Angew. Chem. 72, 267-268 (1960)

19. I. Ugi

"Neues über Isonitrile"

Angew. Chem. 72, 639 (1960)

20. I. Ugi, R. Meyr

"Isonitrile I. Darstellung von Isonitrilen aus monosubstituierten Formamiden durch

Wasserabspaltung"

Chem. Ber. 93, 239-248 (1960)

21. R. Huisgen, I. Ugi

"Mittlere Ringe, XVI. Eigenschaften und Konfiguration der 1,4-Benzlactame"

Chem. Ber. 93, 2639-2704 (1960)

22. I. Ugi, R. Huisgen, D. Pawellek

"Mittlere Ringe XVIII. Die Synthese von w-[2-Carboxy- phenyl]-fettsäuren durch nitrosierende Spaltung von Derivaten des a-Tetralons"

Liebigs Ann. Chem. 641, 63-70 (1961)

23. I. Ugi

"Pentazole"

Angew. Chem. 73, 172 (1961)

24. I. Ugi, U. Fetzer

"Einfache Synthese von Depsipeptid-Derivaten"

Angew. Chem. 73, 621 (1961)

25. I. Ugi, K. Rosendahl

"Triazin-Derivative aus Isonitrilen und Rhodanwasserstoffsäure"

Angew. Chem. 73, 656 (1961)

26. I. Ugi, R. Meyr, M. Lipinski, F. Bodesheim, F. Rosendahl

"Cyclohexyl Isocyanide"

Org. Syntheses 41, 13-15 (1961)

27. I. Ugi, R. Meyr

"o-Tolyl Isocyanide"

Org. Syntheses 41, 101-104 (1961)

28. I. Ugi, C. Steinbrückner

"Isonitrile II. Reaktion von Isonitrilen mit Carbonylverbindungen, Aminen und

Stickstoffwasserstoffsäure"

Chem. Ber. 94, 734-742 (1961) 
29. I. Ugi, U. Fetzer

"Isonitrile III. Die Addition von Carbonsäurechloriden an Isonitrile"

Chem. Ber. 94, 1116-1121 (1961)

30. I. Ugi, F. Bodesheim

"Notiz zur Reduktion von Isonitrilen mit Alkali- und Erdalkalimetallen in flüssigem Ammoniak"

Chem. Ber. 94, 1157-1158 (1961)

31. I. Ugi, F. Beck

"Solvolyse von Carbonsäurederivaten I. Reaktion von Carbonsäurehalogeniden mit Wasser und Aminen"

Chem. Ber. 94, 1839-1850 (1961)

32. I. Ugi, R. Meyr

"Isonitrile V. Erweiterter Anwendungsbereich der Passerini-Reaktion"

Chem. Ber. 94, 2229-2233 (1961)

33. I. Ugi, K. Rosendahl

"Isonitrile VI. Umsetzungen von Isonitrilen mit Ketenen"

Chem. Ber. 94, 2233-2238 (1961)

34. I. Ugi, U. Fetzer

"Isonitrile VII. Die Reaktion von Cyclohexyl-isocyanid mit Phenylmagnesiumbromid"

Chem. Ber. 94, 2239-2243 (1961)

35. I. Ugi, F. Bodesheim

"Isonitrile VIII. Umsetzung an Isonitrilen mit Hydrazonen und Stickstoffwasserstoffsäure"

Chem. Ber. 94, 2797-2801 (1961)

36. I. Ugi, C. Steinbrückner

"Isonitrile IX. a-Addition von Immonium-Ionen und Carbonsäure-Anionen an Isonitrile"

Chem. Ber. 94, 2802-2814 (1961)

37. I. Ugi, W. Betz, U. Fetzer, K. Offermann

"Notiz zur Darstellung von Isonitrilen aus monosubstituierten Formamiden durch Wasserabspaltung mittels Phosgen und Trialkylaminen"

Chem. Ber. 94, 2814-2816 (1961)

38. I. Ugi

"Neuere Methoden der präparativen organischen Chemie IV. Mit Sekundär-Reaktionen gekoppelte aAdditionen von Immonium-Ionen und Anionen an Isonitrile"

Angew. Chem. 74, 9-22 (1962)

Angew. Chem. Int. Ed. Engl. 1, 8-21 (1962)

39. I. Ugi und E. Wischhöfer

"Isonitrile XI. Synthese einfacher Penicillansäure- Derivate"

Chem. Ber. 95, 136-140 (1962)

40. U. Fetzer und I. Ugi

"Isonitrile XII. Synthese von Depsipeptid-Derivaten mittels der Passerini-Reaktion"

Liebigs Ann. Chem. 659, 184-189 (1962)

41. I. Ugi, F. Beck, U. Fetzer

"Solvolyse von Carbonsäurederivaten II. Hydrolyse von Carbonsäure-imidchloriden"

Chem. Ber. 95, 126-135 (1962)

42. F. Beck, E. Böttner, K. Offermann, K. Rosendahl, K. Sjöberg, I. Ugi

"Neue a-Eliminierungen und a-Additionen"

Angew. Chem. 74, 513 (1962)

43. I. Ugi

"Pentazole V. Zum Mechanismus der Bildung und des Zerfalls von Phenyl-pentazol"

Tetrahedron 1963, 1801-1803 (1963) 
44. I. Ugi, K. Offermann

"Asymmetrische 1,3-Induktion bei der a-Addition von Immonium-Ionen und Carboxylat-Anionen an Isonitrile"

Angew. Chem. 75, 917 (1963); Angew. Chem. Int. Ed. Engl. 2, 624 (1963)

45. I. Ugi, F.K. Rosendahl, F. Bodesheim

"Isonitrile XIII. Kondensation von primären Aminen und Ketonen mit Isonitrilen und

Rhodanwasserstoffsäure"

Liebigs Ann. Chem. 666, 54-61 (1963)

46. I. Ugi, F. Bodesheim

"Isonitrile XIV. Umsetzung von Isonitrilen mit Hydrazonen und Carbonsäuren"

Liebigs Ann. Chem. 666, 61-64 (1963)

47. I. Ugi, F.K. Rosendahl

"Isonitrile XV. (1-Cyclohexenyl-isocyanid"

Liebigs Ann. Chem. 666, 65-67 (1963)

48. I. Ugi, E. Böttner

"Isonitrile XVI. Mit O->C-Acyl-Wanderung gekoppelte a-Additionen von N-Alkylchinolinium- und Carboxylat-Ionen der Isonitrile"

Liebigs Ann. Chem. 670, 74-80 (1963)

49. I. Ugi, F. K. Rosendahl

"Isonitrile XVII. Addition von Rhodanwasserstoffsäure an Isonitrile"

Liebigs Ann. Chem. 670, 80-82 (1963)

50. I. Ugi, E. Böttner

"Penicillamin-nitril"

Liebigs Ann. Chem. 670, 83-84 (1963)

51. I. Ugi

"Pentazoles",

in: 'Advances in Heterocyclic Chemistry', Bd. III,Herausg.: A.R. Katritzky,Academic Press, New York 1964, p. 373-383.

52. I. Ugi, K. Offermann, H. Herlinger

"Vorversuche zu Peptid-Synthesen mit Isonitrilen"

Angew. Chem. 76, 613 (1964); Angew. Chem. Int. Ed. Engl. 3, 656 (1964)

53. I. Ugi, K. Offermann

"Isonitrile XVIII. Hydantoin-Imide-(4)"

Chem. Ber. 97, 2276-2281 (1964)

54. I. Ugi, K. Offermann

"Isonitrile XIX. Die Kondensation von Carbonsäuren, Aldehyden und Isonitrilen mit primären

aliphatischen Aminen, die einen abspaltbaren Alkyl- oder Alkenyl-Rest tragen"

Chem. Ber. 97, 2996-3007 (1964)

55. I. Ugi, W. Betz, K. Offermann

"Isonitrile XX. Das Tropylium-Ion als a-Additionspartner von Isonitrilen"

Chem. Ber. 97, 3008-3011 (1964)

56. I. Ugi, K. Offermann, H. Herlinger

"a-Eliminierung und a-Additionen - die Grundprinzipien der Chemie der Isonitrile"

Chimia 18, 278-279 (1964)

57. I. Ugi

"Die Sonderstellung der Isonitrile in der organischen Chemie. a-Additionen und a-Eliminierungen", in: 'Jahrbuch der Akademie der Wissenschaften in Göttingen',

Vandenhoeck \& Rupprecht, Göttingen (1964), S. 21-48.

58. I. Ugi 
"Stereospezifische Synthesen 1. Die Beschreibung korrespondierender Reaktionspaare mit Hilfe antisymmetrischer linearer Freie-Enthalpie-Beziehungen"

Z. Naturforschung 20b, 405-409 (1965)

59. I. Ugi, U. Fetzer, U. Eholzer, H. Knupfer, K. Offermann

"Neuere Methoden der präparativen organischen Chemie IV.

Isonitril-Synthesen"

Angew. Chem. 77, 492-504 (1965); Angew. Chem. Int. Ed. Engl. 4, 452-464 (1965)

60. H. Herlinger, H. Kleimann, K. Offermann, D. Rücker, I. Ugi

"Isonitrile XXI. Asymmetrisch induzierte Synthesen von a-Aminosäure-Derivaten"

Liebigs Ann. Chem. 692, 94-99 (1966)

61. I. Ugi

"a-Additionen an Isonitrile. Tripeladditionen und Vierkomponenten-Kondensationen", in: 'Neuere Methoden der Präparativen Organischen Chemie', Bd. IV, Herausg.: W. Foerst Verlag Chemie, Weinheim 1966, S. 1-36.

62. I. Ugi, U. Fetzer, U. Eholzer, H. Knupfer, K. Offermann

"Isonitril-Synthesen",

in: 'Neuere Methoden der Präparativen Organischen Chemie', Bd. IV, Herausg.: W. Foerst

Verlag Chemie, Weinheim 1966, S. 37-61.

63. E. Ruch, I. Ugi

"Das stereochemische Strukturmodell, ein mathematisches Modell zur gruppentheoretischen

Behandlung der dynamischen Stereochemie"

Theoret. Chim. Acta (Berl.) 4, 287-304 (1966)

64. E. Ruch, A. Schönhofer, I. Ugi

"Die Vandermondesche-Determinante als Näherungsansatz für eine Chiralitäts-Beobachtung, ihre

Verwendung in der Stereochemie und zur Berechnung der optischen Aktivität"

Theoret. Chim. Acta (Berl.) 7, 420-432 (1967)

65. H. Herlinger, H. Kleimann, I. Ugi

"Stereoselektive Synthesen II. Die stereoselektive Acylierung racemischer primärer Amine durch optisch aktive gemischte Anhydride"

Liebigs Ann. Chem. 706, 37-46 (1967)

66. I. Ugi, K. Offermann, H. Herlinger, D. Marquarding

"Stereoselektive Synthesen III. Die Umsetzung von (S)-a-Phenyläthylamin und Isobutyraldehyd mit

Benzoesäure und tert.-Butyl-isocyanid als Modell-Reaktion für stereoselektive Peptid-Synthesen mittels Vierkomponenten-Kondensationen"

Liebigs Ann. Chem. 709, 1-10 (1967)

67. I. Ugi, G. Kaufhold

"Stereoselektive Synthesen IV. Der Reaktionsmechanismus stereoselektiver Vierkomponenten-

Kondensationen"

Liebigs Ann. Chem. 709, 11-28 (1967)

68. E. Schnabel, H. Herzog, P. Hoffmann, E. Klauke, I. Ugi

"Tert.-Butyl-fluorformiat, ein neues Reagens für Peptid-Synthesen"

Angew. Chem. 80, 396 (1968)

Angew. Chem. Int. Ed. Engl. 7, 380 (1968)

69. E. Schnabel, H. Herzog, P. Hoffmann, E. Klauke, I. Ugi

"Synthese und Verwendung von tert.-Butyloxycarbonylfluorid und anderen Fluorkohlensäureestern zur Darstellung säurelabiler Urethan-Derivate von Aminosäuren"

Liebigs Ann. Chem. 716, 175-185 (1968)

70. E. Schnabel, H. Herzog, P. Hoffmann, E. Klauke, I. Ugi

"Tert.-Butyloxycarbonylfluorid als neues Reagens zur Synthese von BOC-Aminosäuren", in: 
'Peptides 1968',

Herausg.: E. Bricas

North-Holland Publishing Company, Amsterdam 1968, S. 91-98.

71. E. Ruch, I. Ugi

"The Stereochemical Analogy Model - A Mathematical Theory of Dynamic Stereochemistry", in: 'Topics in Stereochemistry', Bd. IV,

Herausg.: N. L. Allinger, E.L. Eliel

Wiley, New York 1969, S. 99-125.

72. H. Hagemann, D. Arlt, I. Ugi

"N-Chlor-chlorformimidsäurechlorid aus Chlorcyan und Chlor"

Angew. Chem. 81, 572 (1969; Angew. Chem. Int. Ed. Engl. 8, 606 (1969)

73. I. Ugi

"A Novel Synthetic Approach to Peptides by Computer Planned Stereoselective Four Component

Condensations of a-Ferrocenyl Alkylamines and Related Reactions"

Rec. Chem. Progr. 30, 389-311 (1969)

74. D. Marquarding, P. Hoffmann, H. Heitzer, I. Ugi

"Stereoselective Four Component Condensations of a-Ferrocenylethylamine and its Absolute Configuration"

J. Amer. Chem. Soc. 92, 1969-1971 (1970)

75. D. Marquarding, H. Klusacek, G. Gokel, P. Hoffmann, I. Ugi

"Correlation of Central and Planar Chirality in Ferrocene Derivates"

J. Amer. Chem. Soc. 92, 5389-5393 (1970)

76. G. Gokel, P. Hoffmann, H. Klusacek, D. Marquarding, E. Ruch, I. Ugi

"Die Stereochemie des a-Ferrocenyl-äthyl-Kations"

Angew. Chem. 82, 77-78 (1970); Angew. Chem. Int. Ed. Engl. 9, 64-65 (1970)

77. D. Marquarding, H. Klusacek, G. Gokel, P. Hoffmann, I. Ugi

"Sterisch gezielte Synthesen von planaren Chiroiden"

Angew. Chem. 82, 360-361 (1970); Angew. Chem. Int. Ed. Engl. 9, 371 (1970)

78. I. Ugi, D. Marquarding, H. Klusacek, G. Gokel, P. Gillespie

"Chemie und logische Strukturen"

Angew. Chem. 82, 741-771 (1970); Angew. Chem. Int. Ed. Engl. 9, 703-730 (1970)

79. G. Gokel, P. Hoffmann, H. Kleimann, H. Klusacek, D. Marquarding, I. Ugi

"Remarks on the Asymmetric Lithiation of (S)-1-Ferrocenyl-methyl-2-methylpiperidine and Related Subjects"

Tetrahedron Lett. 21, 1771-1774 (1970)

80. P. Hoffmann, D. Marquarding, H. Kleimann, I. Ugi "Isonitriles",

in: 'The Chemistry of the Cyano Group',

Herausg.: S. Patai, Z. Rappoport

J. Wiley \& Sons, Interscience Publishers, New York 1970, S. 853-883.

81. G.W. Gokel, I.K. Ugi

"Retentive Nucleophile Substitutionen an (R)-a-Ferrocenyläthyl-acetat"

"Retentive Nucleophilic Substitution of (R)-a-Ferrocenyl Acetate")

Angew. Chem. 83, 178-179 (1971); Angew. Chem. Int. Ed. Engl. 10, 191-192 (1971)

82. P. Gillespie, I. Ugi

"Die mechanistischen Grenzfälle der nucleophilen aliphatischen Substitutionen aus neuer Sicht"

Angew. Chem. 83, 493-496 (1971); Angew. Chem. Int. Ed. Engl. 10, 503-506 (1971)

83. P. Gillespie, P. Hoffmann, H. Klusacek, D. Marquarding, S. Pfohl, F. Ramirez, E.A. Tsolis, I. Ugi

"Bewegliche Molekül-Gerüste-Pseudorotation und Turnstile-Rotation pentakoordinierter 
Phosphorverbindungen und verwandte Vorgänge"

Angew. Chem. 83, 691-721 (1971); Angew. Chem. Int. Ed. Engl. 10, 687-715 (1971)

84. I. Ugi, P. Gillespie

"Beschreibung chemischer Systeme und ihrer Umwandlungen durch BE-Matrizen und ihre

Transformation"

Angew. Chem. 83, 980-981 (1971); Angew. Chem. Int. Ed. Engl. 10, 914-915 (1971)

85. I. Ugi, P. Gillespie

"Stoffbilanz-erhaltende Synthesewege und semi-empirische Syntheseplanung mittels elektronischer Datenverarbeitung"

Angew. Chem. 83, 982-985 (1971); Angew. Chem. Int. Ed. Engl. 10, 915-918 (1971)

86. I. Ugi, D. Marquarding, H. Klusacek, P. Gillespie, F. Ramirez

"Berry Pseudorotation and Turnstile Rotation"

Accounts Chem. Res. 4, 288-296 (1971)

87. I. Ugi

"Isonitrile Chemistry",

Academic Press, New York 1971, S. 1-278.

88. P. Hoffmann, G. Gokel, D. Marquarding, I. Ugi

"Isonitrile Syntheses",

in: 'Isonitrile Chemistry',Herausg.: I. Ugi, Academic Press, New York 1971, S. 9-39.

89. D. Marquarding, G. Gokel, P. Hoffmann, I. Ugi

"The Passerini Reaction and Related Reactions",

in: 'Isonitrile Chemistry',Herausg.: I. Ug

Academic Press, New York 1971, S. 133-143.

90. G. Gokel, G. Lüdke, I. Ugi

"Four-Component Condensations and Related Reactions",

in: 'Isonitrile Chemistry', Herausg.: I. Ugi, Academic Press, New York 1971, S. 145-199.

91. G. Gokel, P. Hoffmann, H. Kleimann, H. Klusacek, G. Lüdke, D. Marquarding, I. Ugi

"Peptide Syntheses",

in: 'Isonitrile Chemistry',Herausg.: I. Ugi, Academic Press, New York 1971, S. 201-215.

92. F. Ramirez, I. Ugi

"Turnstile Rearrangement and Pseudorotation in the Permutational Isomerization of Pentavalent Phosphorus Compounds", in: 'Advances in Physical Organic Chemistry', Vol. 9, Herausg.: V. Gold, Academic Press, London 1971, S. 25-126.

93. F. Ramirez, S. Pfohl, E.A. Tsolis, J.F. Pilot, C.P. Smith "Permutational Isomerization of Caged Polycyclis Oxyphosphoranes. Turnstile Rotation and Pseudorotation"

Phosphorus 1, 1-16 (1971)

94. I. Ugi

"The Potential of Four Component Condensations for Peptide Syntheses - A Study in Isonitrile and Ferrocene Chemistry as well as Stereochemistry and Logics of Syntheses"

Intra-Sci. Chem. Rep. 5, 229-261 (1971)

95. F. Batelle, R. Bau, G.W. Gokel, R.T. Oyakawa, I. Ugi

"Absolute Konfiguration eines 1,2-disubstituierten Ferrocen-Derivats mit zwei verschiedenen chiralen Substituenten"

Angew. Chem. 84, 164-165 (1972); Angew. Chem. Int. Ed. Engl. 11, 138 (1972)

96. W.P. Weber, G.W. Gokel, I. Ugi

"Phasenübergangs-Katalyse bei der Hofmannschen Carbylamin-Reaktion"

Angew. Chem. 84, 587 (1972); Angew. Chem. Int. Ed. Engl. 11, 530 (1972) 
97. I. Ugi, P. Gillespie, C. Gillespie

"Chemistry, a Finite Metric Topology - Synthetic Planning, an Exercise in Algebra"

Trans. New York Acad. Sci. II, 34, 416-432 (1972)

98. G. Gokel, I.K. Ugi

"Preparation and Resolution of N,N-Dimethyl-a-Ferrocenylethylamine"

J. Chem. Educ. 49, 294-296 (1972)

99. I. Ugi, F. Ramirez

"The Stereochemistry of Five-Coordinate Phosphorus"

Chemistry in Britain 8, 198-206 (1972)

100. G.W. Gokel, D. Marquarding, I. Ugi

"The Retentive Nucleophilic Displacements of a-Substituted Alkylferrocenes"

J. Org. Chem. 37, 3052-3058 (1972)

101. A.S. Arora, I. Ugi

"Stereoselektive Olefin-Synthesen",

in: 'Houben-Weyl, Methoden der Organischen Chemie', Bd. V/1b, Herausg.: E. Müller,

G. Thieme Verlag, Stuttgart 1972, S. 728-945.

102. F. Ramirez, I. Ugi

"Influence of the Five-Coordinate State of Phosphorus on Reaction Mechanism, Syntheses and Stereochemistry",

in: 'Proceedings of the Vth All Union Conference on the Chemistry of Organophosphorus

Compounds'

Moscow, U.S.S.R., S. 138 (1972)

103. B. Beijer, E.v. Hinrichs, I. Ugi

"Bildung von Isocyaniden bei der Umsetzung on N-monosubstituierten Formamiden mit Phosphanen und Azodicarbonsäure-Derivaten"

Angew. Chem. 84, 957 (1972), Angew. Chem. Int. Ed. Engl. 11, 929 (1972)

104. E. Anders, E. Ruch, I. Ugi

"Experimentelle Prüfung des stereochemischen Strukturmodells am Beispiel der stereoselektiven Acylierung racemischer sekundärer Alkohole mit Phenyltrifluormethylketen"

Angew. Chem. 85, 16-20 (1973), Angew. Chem. Int. Ed. Engl. 12, 25-29 (1973)

105. F. Ramirez, S. Glaser, P. Stern, P.D. Gillespie, I. Ugi

"Fünfgliedrige cyclische Acylphosphate, neue hochreaktive Phosphorylierungsmittel"

Angew. Chem. 85, 39-40 (1973)

Angew. Chem. Int. Ed. Engl. 12, 66-67 (1973)

106. D. Marquarding, F. Ramirez, I. Ugi, P.D. Gillespie

"Austausch-Reaktionen von Phosphor-(V)-Verbindungen und ihre Pentakoordinierten Zwischenstufen"

Angew. Chem. 85, 99-127 (1973), Angew. Chem. Int. Ed. Engl. 12, 91-118 (1973)

107. L.F. Batelle, R. Bau, G.W. Gokel, R.T. Oyakawa, I.K. Ugi

"Absolute Configuration of a 1,2-Disubstituted Ferrocene Derivative with Planar and Central

Elements of Chirality and the Mechanism of the Stereoselective Metalations of Optically Active aFerrocenyl Tertiary Amines"

J. Amer. Chem. Soc. 95, 482-486 (1973)

108. S. Stüber und I. Ugi

"Herstellung von (R,S)-N,N-Dimethyl-1-ferrocenyl-äthylamin"

Synthesis 1973, 309

109. F. Ramirez, J. Marecek, I. Ugi, D. Marquarding

"Caged Polycyclic Oxyphosphoranes derived from Hexafluorobiacetyl"

Phosphorus 3, 91-94 (1973) 
110. R. Ramirez, P. Stern, S.L. Glaser, I. Ugi, P. Lemmen "Selective Phosphorylations of Primary Alcohols in the Presence of Unprotected Secondary Alcohols"

Phosphorus 3, 165-173 (1973)

111. J. Dugundji, I. Ugi "An Algebraic Model of Constitutional Chemistry as a Basis for Chemical Computer Programs" Top. Curr. Chem. 39, 19-64 (1973)

112. F. Ramirez, S.L. Glaser, P. Stern, I. Ugi, P. Lemmen "Five Membered Cyclic Acyl Phosphates"

Tetrahedron 29, 3741-3752 (1973)

113. P.B. Valkovich, G.W. Gokel, I. Ugi

"Asymmetric Induction, Time and Solvent Dependence in the Metallation of Ferrocenylalkyl Ethers" Tetrahedron Lett. 31, 2947-3950 (1973)

114. H.v. Zychlinski, I. Ugi, D. Marquarding "Modellversuche zur Verknüpfung von Peptid-Fragmenten unter Vermeidung racemisierungsanfälliger aktiver Peptid-Derivate" Angew. Chem. 86, 517-518 (1974); Angew. Chem. Int. Ed. Engl. 13, 473-474 (1974)

115. F. Ramirez, S. Lee, P. Stern, I. Ugi, P.D. Gillespie "Intermolecular Ligand Exchange in Five-Coordinate Phosphorus Compounds" Phosphorus 4, 21-23 (1974)

116. F. Ramirez, Y. F. Chaw, J. F. Marecek, I. Ugi "Oxyphosphorane Models for Displacement Reactions of Pyrophosphates" J. Amer. Chem. Soc. 96, 2429-2433 (1974)

117. A.S. Arora, E.v. Hinrichs, I. Ugi "Titration von Isocyaniden"

Z. Anal. Chem. 269, 124 (1974)

118. F. Ramirez, I. Ugi, F. Lin, S. Pfohl, P. Hoffmann, D. Marquarding "Permutational Isomerization of Caged Polycyclic Oxyphosphoranes" Tetrahedron 30, 371-376 (1974)

119. J. Blair, J. Gasteiger, C. Gillespie, P.D. Gillespie, I. Ugi "Representation of the Constitutional and Stereochemical Features of Chemical Systems in the Computer Assisted Design of Syntheses" Tetrahedron 30, 1845-1859 (1974)

120. J. Gasteiger, P.D. Gillespie, D. Marquarding, I. Ugi "From van't Hoff to Unified Perspectives in Molecular Structure and Computer Oriented Representation" Topics Curr. Chem. 48, 1-37 (1974)

121. J. Blair, J. Gasteiger, C. Gillespie, P.D. Gillespie, I. Ugi "CICLOPS - A Computer Program For the Design of Syntheses on the Basis of a Mathematical Model", in: 'Computer Representation and Manipulation of Chemical Information', Herausg.: W.T. Wipke, S.R. Heller, R.J. Feldmann, E. Hyde John Wiley, New York 1974, S. 129-145.

122. I. Ugi

"Eine neue Phase der Chemie. Logisches Strukturmodell und Computerprogramme zur Darstellung chemischer Verbindungen und Reaktionen"

IBM Nachrichten 24, 180-184 (1974)

123. I. Ugi, J. Gasteiger, J. Brandt, J. Brunnert, W. Schubert "Chemische Syntheseplanung mit dem Computer"

IBM Nachrichten 24, 185-189 (1974) 
124. S. Stüber, I. Ugi

"6-Amino- und 6-Dimethylamino-2,4-heptadien-tricarbonyleisen"

Synthesis 1974, 437-440

125. F. Ramirez, I. Ugi

"Recent Developments in Oxyphosphorane Chemistry"

Bull. Soc. Chim. (France) 1974, 453-470

126. I. Ugi, F. Ramirez, E.v. Hinrichs, P. Lemmen, J. Firl

"Silyl Esters of a Five-membered Cyclic Acyl Phosphate"

Chem. Commun. 1974, 979-980

127. G. Eberle, D. Marquarding, I. Ugi, R. Urban

"Organometallic Reagents in Peptide Synthesis",

in: 'Abstracts of the international Symposium on Metals in Organic Chemistry in Venice', Sept. 1974, C1, 1-7 (1974)

128. F. Ramirez, I. Ugi

"Phosphorylating Reagents for Oligonucleotide Synthesis"

Proceed. Int. Conf. 1974 on Recent. Dev. Oligonucleotide Synth. Chem. Minor Bases tRNA", Herausg.: Paryzek, Zdzislaw; Uniw. im. Adama Mickiewicza, Poznan, Pol. 1974, S. 53-88.

129. F. Ramirez, I. Ugi

"Preparation, Reaction Mechanism, and Stereochemistry of Compounds with a five-coordinated Phosphorus Atom"

Khim. Primen. Fosfororg. Soedin., T. Konf., 5th 1972; Herausg.: M.I. Kabachnik, E.E. Nifant'ev;

"Nauka", Moskau, USSR 1974

130. I. Ugi, A. Arora, H. Burghard, G. Eberle, H. Eckert, G. George, G. Gokel, H. Herlinger, E.v. Hinrichs, P. Hoffmann, H. Kleimann, H. Klusacek, H.L. Lam, D. Marquarding, H.S. Nah, K. Offermann, D. Rehn, S. Stüber, M. Tamasi, R. Urban, L. Wackerle, S. Zahr, H.v. Zychlinski "Four Component Condensations (4CC), a Potential Alternative to Conventional Peptide Synthesis the Solution of the Stereoselectivity and Auxiliary Group Removal Problems",

in: 'Peptides 1974', Herausg.: Y. Wolman, J. Wiley \& Sons, Israel University Press, Jerusalem 1975, S. 71-92.

131. T. El Gomati, D. Lenoir, I. Ugi

"Experimenteller Nachweis eines neuartigen mechanistischen Grenztypus der aliphatischen nucleophilen Substitution"

Angew. Chem. 87, 66-67 (1975); Angew. Chem. Int. Ed. Engl. 14, 59-61 (1975)

132. R. Urban, I. Ugi

"Asymmetrisch induzierte Vierkomponenten-Kondensationen mit extrem hoher Stereoselektivität und Selektivitäts-Multiplikation"

Angew. Chem. 87, 67-69 (1975); Angew. Chem. Int. Ed. Engl. 14, 61-62 (1975)

133. H. Eckert, I. Ugi

"Kobalt(I)-phthalocyanin-Salze, in neutralem Medium stabile "supernukleophile" Vitamin-B12Modellsubstanzen"

Angew. Chem. 87, 847-848 (1975), Angew. Chem. Int. Ed. 14, 825-826 (1975)

134. H.L. Carrel, H.M. Berman, J.S. Ricci, Jr., W.C. Hamilton, F. Ramirez, J.F. Marecek, L. Kramer, I. Ugi

"Crystal and Molecular Structure of a Caged Polycyclic Tetraoxycarbonphosphorane, (PO4C)(C6H5CN)(CF3)2(C6H9)"

J. Amer. Chem. Soc. 97, 38-46 (1975)

135. F. Ramirez, J.F. Marecek, I. Ugi

"Synthesis of Unsymmetrical Phosphodiesters by Means of Cyclic Enediol Pyrophosphates"

J. Amer. Chem. Soc. 97, 3809-3817 (1975) 
136. H. Eckert, G.N. Schrauzer, I. Ugi

"Fragmentierungen durch Supernucleophile - I. Der 2-Chloräthoxy-carbonyl-Restals N-terminale, mit Supernucleophilen selektiv abspaltbare Schutzgruppe von Aminosäuren"

Tetrahedron 31, 1399-1401 (1975)

137. F. Ramirez, J.F. Marecek, I. Ugi, P. Lemmen, D. Marquarding

"Phosphate and Oxyphosphorane Models for Adenosine-3',5'-cyclophosphate" Phosphorus 5, 73-84 (1975)

138. F. Ramirez, J.F. Marecek, I. Ugi

"A New Reagent for the Phosphorylative Coupling of two Different Alcohols" Synthesis 1975, 99-100

139. L. Wackerle, I. Ugi

"Verbesserte Herstellung von t-Butoxycarbonyl-fluorid und dessen Verwendung zur Synthese von 1Boc-3-formylindol, einem neuen Reagenz zur Verknüpfung von Peptid-Fragmenten"

Synthesis 1975, 598-599

140. G. Eberle, I. Ugi

"Wiedergewinnung der chiralen a-Ferrocenylalkylamine bei der stereoselektiven Peptid-Synthese durch Vierkomponentenkondensation"

Angew. Chem. 88, 509-510 (1976; Angew. Chem. Int. Ed. Engl. 15, 492-493 (1976)

141. R. Urban, G. Eberle, D. Marquarding, D. Rehn, H. Rehn, I. Ugi

"Synthese eines isomerenfreien Tetravalin-Derivates durch stereoselektive Vier-Komponenten-

Kondensation und exponentielle Selektivitätsverstärkung"

Angew. Chem. 88, 644-646 (1976); Angew. Chem. Int. Ed. Engl. 15, 627-628 (1976)

142. H. Eckert, I. Ugi

"Neue Schutzgruppentechnik - Spaltung von b-Halogenalkyl-Estern mit supernucleophilem

Cobalt(I)-phthalocyanin"

Angew. Chem. 88, 717-718 (1976); Angew. Chem. Int. Ed. Engl. 15, 681 (1976)

143. T. El Gomati, J. Gasteiger, D. Lenoir, I. Ugi

"Über den stereochemischen Verlauf von SN2-Reaktionen an cis- und trans-3-Äthoxycyclobutyl-

Verbindungen"

Chem. Ber. 109, 826-832 (1976)

144. I. Ugi, P. Lemmen

"Notiz über eine verbesserte Methode zur Darstellung von 5t-Acetyl-2r-methoxy-5c-methyl-2,4dioxo-1,3,2l5-dioxaphospholan (cis-Methyl-CAP)"

Chem. Ber. 109, 3738-3739 (1976)

145. J. Dugundji, D. Marquarding, I. Ugi

"Chirality and Hyperchirality"

Chemica Scripta 9, 74-96 (1976)

146. J. Albanbauer, K. Burger, E. Burgis, D. Marquarding, L. Schabl, I. Ugi

"Dynamische Stereochemie der (4-1,4,215-Oxaza-phospoline"

Liebigs Ann. Chem. 1976, 36-53

147. J. Dugundji, P.D. Gillespie, d. Marquarding, I. Ugi, F. Ramirez

"Metric Spaces and Graphs Representing the Logical Structure of Chemistry",

in: 'Chemical Applications of Graph Theory', Herausg.: A.T. Balaban, Academic Press, London 1976, S. 107-174.

148. K. Burger, D. Marquarding, I. Ugi, H. Gold

"Reaktivität der Carbonyl-Gruppe",

in: Houben-Weyl, 'Methoden der Organischen Chemie', Bd. VII, Teil 2b, Herausg.: E. Müller,

Thieme, Stuttgart 1976, S. 1912-1926.

149. H. Eckert, I. Ugi 
"Fragmentierung mit Supernukleophilen. II. Ligandenbedingte, grundlegende Unterschiede im Reaktionsverhalten von Kobalt(I)-Supernukleophilen beim Umsetzen mit N-Phenyl-O-[bhalogenäthyl]-urethan bzw. dessen N-Methyl-Derivat"

J. Organomet. Chem. 118, C55-C58 (1976)

150. H. Eckert, I. Ugi

"Fragmentierung mit Supernukleophilen. III. Die reduktive Fragmentierung von 2-Benzoyloxy-äthylkobalt(III)-phthalocyanin als Modellreaktion für eine neue Schutzgruppentechnik bei

Peptidsynthesen"

J. Organomet. Chem. 118, C59-C61 (1976)

151. F. Ramirez, I. Ugi

"New Syntheses of Unsymmetrical Phosphodiesters Based on the Oxyphosphorane Concept" Phosphorus Sulfur 1, 231-244 (1976)

152. I. Ugi, H. Aigner, B. Beijer, D. Ben-Efraim, H. Burghard, P. Bukall, G. Eberle, H. Eckert, D.

Marquarding, D. Rehn, R. Urban, L. Wackerle, H.v. Zychlinsky

"New Methods for Peptide Synthesis with Organometallic Reagents and Isocyanides",

in: 'Peptides 1976', Herausg.: A. Loffet, Editions de L'Universite, Bruxelles 1976, S. 159-181.

153. G. Skorna, I. Ugi

"Isonitril-Synthese mit Diphosgen"

Angew. Chem. 89, 267-268(1977); Angew. Chem. Int. Ed. Engl. 16, 259-260 (1977)

154. T. El Gomati, J. Firl, I. Ugi

"Notiz zur Konstitutionsermittlung der Umsetzungsprodukte von Diphenylketen mit Isonitrilen"

Chem. Ber. 110, 2012-2015 (1977)

155. R. Urban, D. Marquarding, P. Seidel, I. Ugi, A. Weinelt

"Notiz zur Synthese optisch aktiver a-Isocyancarbonsäure-Derivate für Peptidsynthesen mittels VierKomponenten-Kondensation (4CC)"

Chem. Ber. 110, 2012-2015 (1977)

156. D. Marquarding, A. Schutz, I. Ugi

"Mechanismus der Umlagerung von Dimethylsulfamidsäuremethylester zum TrimethylammoniumN-sulfonat"

Chem. Ber. 110, 2656-2658 (1977)

157. J. Dugundji, D. Marquarding, I. Ugi

"The Indeterminateness of Chirality Functions in Hyperchiral Families"

Chemica Scripta 11, 17-24 (1977)

158. J. Brandt, J. Friedrich, J. Gasteiger, C. Jochum, W. Schubert, I. Ugi

"Computers as an Aid in Organic Synthesis Design", in:

'Computers in Chemical Education and Research', Herausg.: E.V. Ludena, N.H. Sabelli, A.C. Wahl, Plenum Press, New York 1977, S. 337-355

159. J. Brandt, J. Friedrich, J. Gasteiger, C. Jochum, W. Schubert, I. Ugi

"Computer Programs for the Deductive Solution of Chemical Problems on the Basis of a

Mathematical Model of Chemistry",

in: 'Computer Assisted Organic Synthesis',Symposium Series No. 61, Herausg.: W.T. Wipke, W.J.

Howe, Amer. Chem. Soc., Washington DC 1977, S. 33-59.

160. I. Ugi, G. Eberle, H. Eckert, I. Lagerlund, D. Marquarding, G. Skorna, R. Urban, L. Wackerle, H.v. Zychlinski

"The Present Status of Peptide Synthesis by Four-Component Condensation and Related Chemistry", in: 'Peptides', (Proc. of the 5th Amer. Peptide Sympos.), Herausg.: M. Goodman, J. Meienhofer, Halsted Press, Wiley \& Sons, New York 1977, S. 484-487.

161. D. Marquarding, H. Burghard, I. Ugi, R. Urban, H. Klusacek

"A New Method for the Determination of the Absolute Configuration and Optical Purity of Chiral 
Ferrocene Derivatives through Stereorelating Metallation of a-Dimethylamino Alkylferrocenes"

J. Chem. Res.(S) 1977, 82-83; (M) 1977, 0915-0958

162. D. Rehn, I. Ugi

"Isocyanides as Activating Reagents for Carboxylic Acids; Ester Syntheses under Mild Conditions"

J. Chem. Res.(S) 1977, 119; (M) 1977, 0501-1506

163. H. Eckert, D. Lenoir, I. Ugi

"Stabile tertiäre und sekundäre Cobaloxime. Reaktion von Cobaloxim(I) mit Bromiden aus der Reihe des Adamantans und Norborans"

J. Organomet. Chem. 141, C23-C27 (1977)

164. J. Brandt, C. Jochum, I. Ugi, P. Jochum

"Unlimited Non-Linear Selectivity Effects in Systems of Independent Parallel Reactions as a Basis for New Chemical Separation Techniques"

Tetrahedron 33, 1353-1363 (1977)

165. H. Eckert, I. Lagerlund, I. Ugi

"Fragmentation with Supernucleophiles - VI. b-Haloalkyl Groups as Functional Protection in Peptide Synthesis. A Kinetic Study of the Reaction of the Cobalt(I)phthalocyanine Anion with Organic Halides"

Tetrahedron 33, 2243-2247 (1977)

166. A. Gieren, B. Dederer, G. George, D. Marquarding, I. Ugi

"Die Bildung von Aminomalonsäure-Derivaten als Nebenreaktion von VierkomponentenKondensation (4CC) und die röntgenographische Ermittlung der Struktur eines Vertreters" Tetrahedron Lett. 18, 1503-1506 (1977)

167. A. Gieren, B. Dederer, I. Ugi, S. Stüber

"Übergangsmetallkatalysierte Selbstkondensation von (E)-Benzaldoxim und röntgenographische Strukturbestimmung des Produktes"

Tetrahedron Lett. 18, 1507-1510 (1977)

168. H. Eckert, M. Listl, I. Ugi

"Der 2,2,2-Trichlor-tert.-butyloxycarbonyl-(TCBOC)-Rest, eine säure- und basestabile, schonend abspaltbare Schutzgruppe"

Angew. Chem. 90, 388-389 (1978); Angew. Chem. Int. Ed. Engl. 17, 361-362 (1978)

169. R. Herrmann, I. Ugi

"Direkte Bildung des a-Ferrocenylisobutyl-Kations aus Ferrocen und Isobutyraldehyd"

Angew. Chem. 90, 734-735 (1978); Angew. Chem. Int. Ed. Engl. 17, 689-690 (1978)

170. G. Skorna, R. Stemmer, I. Ugi

"Isocyanmethyl-polystyrol"

Chem. Ber. 111, 806-810 (1978)

171. G. Skorna, I. Ugi

"Bifunktionelle Isocyanide als Reagenzien zur Einführung von Isocyangruppen in Polystyrol-

Divinylbenzol-Copolymere"

Chem. Ber. 111, 3965-3968 (1978)

172. I. Ugi, J. Brandt, J. Friedrich, J. Gasteiger, C. Jochum, P. Lemmen, W. Schubert

"The Deductive Solution of Chemical Problems by Computer Programs on the Basis of a

Mathematical Model of Chemistry"

Pure \& Appl. Chem. 50, 1303-1318 (1978)

173. W. Schubert, I. Ugi

"Constitutional Symmetry and Unique Descriptors of Molecules"

J. Am. Chem. Soc. 100, 37-41 (1978) 
174. E.v. Hinrichs, I. Ugi

"Synthesis of 1,3,4,2-Dioxyphospholes from Arylhydroxamic Acids and Phosphorus Halides"

J. Chem. Research (S) 1978, 338; (M) 1978, 3973-3993

175. P. Bukall, I. Ugi

"Photolytic Removal of a 4-Pyridyl-(t-butyl-amino-carbonyl)methyl Auxiliary Group from the Amide Nitrogen of a Four Component Condensation Product"

Heterocycles 11, 467-470 (1978)

176. I. Ugi

"Die Stadien der organischen Synthese seit Liebig"

Gießener Universitätsblätter, Heft 2, 67-79 (1978)

177. G. Eberle, I. Lagerlund, I. Ugi, R. Urban

"Preparation of 1-Ferrocenyl-2-methyl-1-propylamine, a Highly Effective Chiral Template in Asymmetrically Induced Synthesis"

Tetrahedron 34, 977-980 (1978)

178. J. Dugundji, R. Kopp, D. Marquarding, I. Ugi

"A Quantitative Measure of Chemical Chirality and Its Application to Asymmetric Synthesis" Topics Curr. Chem. 75, 165-180 (1978)

179. R. Urban, D. Marquarding, I. Ugi

"Asymmetrische Synthesen mit unbegrenzter Stereoselektivität. Die Synthese isomerenfreier PeptidDerivate mittels stereoselektiver Vierkomponenten-Kondensation"

Hoppe-Seyler's Z. f. Physiol. Chem. 359, 1541-1552 (1978)

180. I. Ugi, D. Marquarding, R. Urban

"Extremely Stereoselective Syntheses of Peptide by 4CC",

in: 'Proceedings of the Second FRG-USSR Symposium on Chemistry of Peptides and Proteins', in

Grainau-Eibsee, Obb., Mai 1978, MPG,München 1978, S. 29-31

181. R. Urban, I. Ugi

"The Synthesis of Naturally Occurring Peptide Sequences by Stereoselective Four Component Condensation", in: 'Proceedings of the Second FRG-USSR Symposium on Chemistry of Peptides and proteins', in Grainau-Eibsee,Obb., Mai 1978, MPG, München 1978,S. 32-33

182. H. Eckert, M. Listl, I. Ugi

"2,2,2-Trichloro-tert.-butyloxycarbonyl [TCBOC], a Protection Group stable towards Acids and Bases and selectively cleavable under mild Conditions"

in: 'Proceedings of the Second FRG-USSR Symposium on Chemistry of Peptides and Proteins', in Grainau-Eibsee,Obb., Mai 1978,MPG, München 1978, S. 146-148.

183. I. Ugi, H. Bauer, J. Brandt, J. Friedrich, J. Gasteiger, C. Jochum, W. Schubert

"Scope and Limitations of the Deductive Solution of Chemical Problems by Computer Programs", in: 'Textes Conf. Cadre Congr. Int. 'Contrib. Calc. Electron. Dev. Genie Chim. Chim. Ind.' 1978, A, 140-141

184. I. Ugi, J. Bauer, J. Brandt, J. Friedrich, J. Gasteiger, C. Jochum, W. Schubert

"Neue Anwendungsgebiete für Computer in der Chemie"

Angew. Chem. 91, 99-111 (1979); Angew. Chem. Int. Ed. Engl. 18, 111-123 (1979)

185. R. Herrmann, I. Ugi

"Eintopfsynthesen von a-Ferrocenylalkyleaminen"

Angew. Chem. 91, 1023-1024 (1979); Angew. Chem. Int. Ed. Engl. 18, 956-957 (1979)

186. G. Skorna, I. Ugi

"Schonende Veresterung von N-terminal geschützten Aminosäuren mittels der Vier-Komponenten-

Kondensation (4CC)"

Chem. Ber. 112, 776-777 (1979) 
187. W. Schubert, I. Ugi

"Darstellung chemischer Strukturen für die computergestützte deduktive Lösung chemischer Probleme"

Chimia 33, 183-191 (1979)

188. H. Eckert, I. Ugi

"Spaltung b-halogenierter Urethane mit Kobalt(I)-phthalocyanin; eine neue Schutzgruppentechnik für Peptid-Synthesen"

Liebigs Ann. Chem. 1979, 278-295

189. I. Ugi, J. Bauer, J. Brandt, J. Friedrich, J. Gasteiger, C. Jochum, W. Schubert, J. Dugundji

"Ein Mathematisches Modell der konstitutionellen Chemie und darauf beruhende

Computerprogramme"

Inform. Comm. Math. Chem. 6, 159-176 (1979)

190. J. Friedrich, I. Ugi

"Substructure Searching and Structure Property Locating by Means of Subgraph Generation"

Inform. Commun. Math. Chem. 6, 201-211 (1979)

191. S. Zahr, I. Ugi

"4,4,4-Trichloro-2-butenal and Analogs as Reagents for Peptide Synthesis"

Synthesis 4, 266-267 (1979)

192. W. Schubert, I. Ugi

"Simulation of Chemical Reactions by Basetransformation of Ensembles of Molecules",

in: 'Papers contributed to the IV. International Conference on Computers in Chemistry. II', Juni 1978;

Herausg.: V.A. Koptjug, Novosibirskij Inst. Organ. Chimii, SO AN SSR, Novosibirsk (1979)

193. H. Eckert, W. Breuer, J. Geller, I. Lagerlund, M. Listl, D. Marquarding, S. Stüber, I. Ugi, S. Zahr, H.v. Zychlinski

"New Methods in Peptide Synthesis, based on Supernucleophiles"

Pure Appl. Chem. 51, 1219-1233 (1979)

194. H.A. Kellner, I. Ugi

"(2-Trichlormethyl-2-propyl)-chlorophosphate als Phosphorylierungs-Reagentien"

Z. Naturforschung 34b, 1159-1161 (1979)

195. A. Schutz, I. Ugi

"Die Synthese eines Cephamderivats mittels Vierkomponenten-Kondensation"

Z. Naturforschung 34b, 1303-1306 (1979)

196. H. Dauner, D. Lenoir, I. Ugi

"Der retentive Verlauf nukleophiler Substitutionen an 7- exo-Norcaryltriflat"

Z. Naturforschung 34b, 1745-1749 (1979)

197. A. Schutz, I. Ugi, H. J. Kabbe

"Synthesis of a Penicillin Derivative by a Four-Component Condensation"

J. Chem. Res. (S) 1979, 157; (M) 1979, 2064-2071

198. "The Four Component Synthesis", in: 'The Peptides', Vol.2.

Herausg.: M. Meienhofer, E. Gross; Academic Press, New York 1979, p.365

199. R. Urban, D. Marquarding, I. Ugi

"The Synthesis of Alamethicin-Fragments by Four Component Condensation",

in: Proc. Am. Pept. Symp., 6th, S. 727-729 (1979)

200. C. Jochum, J. Gasteiger, I. Ugi

"Das Prinzip der minimalen chemischen Distanz (PMCD)"

Angew. Chem. 92, 503-513 (1980); Angew. Chem. Int. Ed. Engl. 19, 495-505 (1980)

201. J. Friedrich, I. Ugi

"Substructure Retrieval and the Analysis of Structure- Activity Relations on the Basis of a Complete 
and Ordered Set of Fragments"

J. Chem. Res. (S) 1980, 70; (M) 1980, 1301-1380; (M) 1980, 1401-1497; (M) 1980, 1501-1550

202. I. Ugi, J. Bauer, J. Brandt, J. Friedrich, J. Gasteiger, C. Jochum, W. Schubert, J. Dugundji

"Computer Programs for the Deductive Solution of Chemical Problems on the Basis of Mathematical Model - A Systematic Bilateral Approach to Reaction Pathways", in: 'Computational Methods in Chemistry', Herausg.: J. Bargon, Plenum Press, New York 1980, S. 275-300.

203. G. Meggendorfer, R. Schwarz, I. Ugi

"Darstellung von 2-(b-Chloräthyoxy)-2-oxo-4,5-dimethyl-1,3,2.15-dioxyphospholen, einem neuen Phosphorylierungsmittel"

Tetrahedron Lett. 21, 2493-2496 (1980)

204. P. Seidel, I. Ugi

"4,4,4-Trichlor-(2-1-butenyl-dichlorphosphat und -dichlorphosphit, zwei Reagentien für die Synthese von Oligonukleotiden"

Z. Naturforschung 35b, 1584-1586 (1980)

205. I. Ugi, W. Breuer, P. Bukall, S. Falou, R. Herrmann, D. Marquarding, P. Seidel, R. Urban

"Neue Aspekte der Peptidsynthese mittels Vierkomponentenkondensation",

in: 'Proc. of III USSR-FRG Symposium on Chemistry of Peptides and Proteins' Makhachkala, Okt. 1979, Publishing Office NAUKA, Moscow 1980, S. 56

206. R. Urban, D. Marquarding, I. Ugi

"The Synthesis of Peptides with Unusual Amino Acids with Four Component Condensation", in: 'Proc. of III USSR-FRG Symposium on Chemistry of Peptides and Proteins', Makhachkala, Okt. 1979,Academy of Science of the USSR; Publishing Office NAUKA, Moscow 1980, S. 57-59.

207. J. Friedrich, I. Ugi

"CORREL II, an improved Substructure Search System and a Structure/Activity Analysis System with a Pre-generated Hierarchic Network of Substructures",

in: Proc. of the Table Ronde, Roussel Uclaf, Paris 1980, S. 26-28

208. I.K. Ugi

"Prediction of Environmental Properties on the Basis of a Mathematical Model of Constitutional

Chemistry",

Comm. Eur. Communities [Rep.] EUR 1980,

EUR 6388, Environ. Res. Programme, 663-666 (1980)

209. J. Dugundji, J. Showell, R. Kopp, D. Marquarding, I. Ugi

"A Group Theoretical Analysis of Conformational Flexibility"

Isr. J. Chem. 20, 20-35 (1980)

210. D. Lenoir, H. Dauner, I. Ugi, A. Gieren, R. Hübner, V. Lamm

"Reaktion von Arylbromiden mit Cobaloxim(I). röntgenstrukturanalyse des Umsetzungsproduktes von cis-3-Ethoxycyclobutylbrosylat mit (Pyridin)cobaloxim(I)"

J. Organomet. Chem. 1981, C39-C42 (1980)

211. H.A. Kellner, R.G.K. Schneiderwind, H. Eckert, I.K. Ugi

"Bis(2,2,2-trichlor-1,1-dimethylethyl)monochlorophosphat, ein selektives Reagens für Phosphorylierung und Schutz der 5'-OH-Gruppe von Nucleosid-Derivaten"

Angew. Chem. 93, 581-582 (1981); Angew. Chem. Int. Ed. Engl. 20, 577-578 (1981)

212. R. Schwarz, I. Ugi

"Synthese hochreaktiver cyclischer Endiolphosphate und cyclischer Acylphosphate durch direkten phosphorylierenden Ringschluß"

Angew. Chem. 93, 836-838 (1981); Angew. Chem. Int. Ed. Engl. 20, 789-791 (1981)

213. P. Bukall, I. Ugi

"Cleavage of 4-Pyridylglycine Derivates by Ni(II)-phthalocyanine Catalyzed Autoxidation - Model 
Experiments for Peptide Segment Coupling by Four Component Condensations

Heterocycles 15, 381-390 (1981)

214. R. Herrmann, I. Ugi

"The Electrophilic Substitution of Ferrocene by Protonated Carbonyl Compounds"

Tetrahedron 37, 1001-1009 (1981)

215. R.G.K. Schneiderwind, I. Ugi

"Die 2,2,2-Trichlor-tert-butyloxycarbonyl-Gruppe als N-Schutzgruppe bei Oligonukleotidsynthesen"

Z. Naturforschung 36b, 1173-1175 (1981)

216. R. Arshady, I. Ugi

"Solid Phase Peptide Synthesis by Four Component Condensation; Peptide Formation on an Isocyano Polymer Support"

Z. Naturforschung 36b, 1202-1203 (1981)

217. P. Seidel, I. Ugi

"Die Photoaddition von Bromtrichlormethan an Acrolein-diethylacetal und die Synthese von 4,4,4-

Trichlor-(2-butenal"

Z. Naturforsch., 36b, 1655-1657 (1981)

218. I. Ugi

"Die historische Entwicklung der Begriffe und logischen Grundlagen der Chemie - der Weg bis zur

Computerchemie"

Internationales Döbereiner-Kolloquium, Herausg.: F. Bolck; Friedrich-Schiller-Universität Jena 1981, S. 57-69

219. I. Ugi, J. Bauer, J. Brandt, J. Dugundji, R. Frank, J. Friedrich, A.v. Scholley, W. Schubert

"Mathematical Model of Constitutional Chemistry and System of Computer Programs for Deductive Solution of Chemical Problems",

in: 'Data Processing in Chemistry',Herausg.: Z. Hippe, Elsevier Scientific Publishing Company, Amsterdam (1981), S. 219-228.

220. I. Ugi, D. Marquarding

"Synthesis by Four Component Condensation (Ugi Reaction)"

Yu Chi Hua Hsueh 1, 49-57 (1981)

221. R. Arshady, I. Ugi

"Synthese makromolekularer Isocyanide mit allgemeiner Lösungsmittel-Verträglichkeit - Neuartige Polymerträger für Festphasen-Synthesen"

Angew. Chem. 94, 367 (1982); Angew. Chem. Int. Ed. Engl. 21374 (1982); Angew. Chem. Suppl. 1982, 761-768

222. R. Herrmann, I. Ugi

"Chirale zweikernige Carbenkomplexe aus (R,R)-1-(1- Dimethylaminoethyl)-2-lithioferrocene and Hexacarbonylwolfram"

Angew. Chem. 94, 798-799 (1982); Angew. Chem. Int. Ed. Engl. 21, 788 (1982); Angew. Chem.

Suppl. 1982, 1630-1642

223. I. Ugi, D. Marquarding, R. Urban

"Synthesis of Peptides by Four-Component Condensation",

in: 'Chemistry and Biochemistry of Amino Acids, Peptides and Proteins', Bd. 6.

Herausg.: B. Weinstein, Marcel Dekker, New York 1982, S. 245-289.

224. P. Seidel, I. Ugi

"Die Photoaddition von Bromtrichlormethan an Allyl-Systeme"

Z. Naturforschung 37b, 376-379 (1982)

225. P. Seidel, I. Ugi

"Die Synthese von 1-substituierten 4,4,4-Trichlor-(2-trans-butenen"

Z. Naturforschung 37b, 499-503 (1982) 
226. C. Jochum, J. Gasteiger, I. Ugi, J. Dugundji

"The Principle of Minimum Chemical Distance and the Principle of Minimum Structure Change"

Z. Naturforschung 37b, 1205-1215 (1982)

227. G. Giesemann, E.v. Hinrichs, I. Ugi

"Synthesis of Chiral a-Isocyano Esters and other Base-sensitive Isocyanides with Oxomethylenebis(3H+-Imidazolium)bis (methanesulphonate), a Versatile Dehydrating Reagent"

J. Chem. Res. (S) 1982, 79

228. W. Breuer, I. Ugi

"A Fast and Convenient Test for the Racemization of Amino Acids during Peptide Syntheses based on 19F-Nuclear Magnetic Resonance Spectroscopy"

J. Chem. Res. (S) 1982, 271; (M) 1982 2901-2945

229. I. Ugi

"Die Evolution der organischen Chemie und ihre Meilensteine - Von Wöhler bis zur

Computerchemie"

Chimica Didactica 8, 103-122 (1982)

230. J. Bauer, I. Ugi

"Chemical Reactions and Structures without Precedent generated by Computer Programs."

J. Chem. Res. 1982, (S) 298; (M) 1982, 3101-3196 u. 3201- 3260

231. I. Ugi

"Von Isocyaniden via Vierkomponenten-Kondensationen zu Antibiotika-Synthesen"

Angew. Chem. 94, 826-835, 1982

Angew. Chem. Int. Ed. Engl. 21, 810-819, (1982)

232. I. Ugi, W. Breuer, P. Bukall, S. Falou, G. Giesemann, R. Herrmann, G. Hübener, D. Marquarding, I. Seidel, R. Urban

"New Aspects of Peptide Synthesis by Four Component Condensations", in: 'Chemistry of Peptides and Proteins', Bd. 1

Herausg.: W. Voelter, E. Wünsch, Y. Orchimickov, V. Ivanov

De Gruyter, Berlin 1982, S. 203-208.

233. I. Ugi, J. Geller

"The selective Cleavage of Carbonamide Groups, and the Synthesis of b-Lactam Antibiotics by Four Component Condensation"

Chem. Scripta 22, 85-89 (1983)

234. I. Ugi, G. Giesemann

"Chloralimine [N-(2,2,2-Trichlorethyliden)-amine]"

Synthesis 1983, 788-789

235. P. Lemmen, I. Ugi

"Synthese und Bestimmung der absoluten Konfiguration des medialen (1R,1S,2S) - und des distalen (S,S)-1,1'-Dimethyl- 2,2-Spiro-Biindans"

Liebigs Ann. Chem. 1983, 688-677

236. I. Ugi, R. Herrmann, A. J. L. Pombeiro

"Etudo de propriadef redox de complexos ferrocenos substitudos."

in: Proc. d. Vier-Nationen-Treffens in Brtaga, Portugal, Port Chem. Ges., 1983

237. I. Ugi, R. G. K. Schneiderwind

"Die 2,2,2-Trichlor-t.-butyloxycarbonyl-Gruppe, eine neue N-Schutzgruppe für

Oligonucleotidsynthesen"

Tetrahedron 30, 2207-2210 (1983)

238. I. Ugi, J. Dugundji, R. Kopp, D. Marquarding

"Perspectives in Theoretical Stereochemistry"

Lecture Note Series, Bd. 36, Springer, Heidelberg 1984, S. 1-265. 


\section{I. Ugi, I. Götz}

"The Synthesis of 2-Chloro-2-oxo-4.5-dimethyl-1.3.2.15- dioxaphospholene (CEP Chloride)" Heterocycles 21, 265-269 (1984)

240. I. Ugi, R. Herrmann, H. Martin

"Synthesis of Chiral N-(Ferrocenylalkyl)hydroxylamines"

J. Organomet. Chem. 269, 87-89 (1984)

241. I. Ugi, R. Obrecht, S. Tour, "Recent Developments in b-Lactam Synthesis by Four Component Condensation" Heterocycles 21, 271-277 (1984)

242. I. Ugi, R. Schneiderwind-Stöcklein

"Der 2-Trichlormethyl-2-propyl-Rest als Phosphatschutz in der Oligonucleotid-Synthese"

Z. Naturforschung 39b, 968-971 (1984)

243. I. Ugi

"De Jove et de bove"

Nachr. Chem. Techn. Lab. 31, 276 (1984)

244. I. Ugi

"Pentazoles"

in: 'Comprehensive Heterocyclic Chemistry', Bd. 5, Herausg.: A.R. Katritzky, C.W. Rees, Pergamon, New York 1984, S. 839-845

245. I. Ugi, H. Aigner, M. L. V. Arnaez, G. Glahsl, P. Lemmen, R. Stöcklein-Schneiderwind, M. BallaTamasi

"Synthesen mit Derivaten von Nucleosiden, a-Aminosäuren, Peptiden und b-Lactam-Antibiotika als Anwendungsbeispiele für HPLC. Studium und Optimierung selektiver chemischer Reaktionen mittels HPLC",

in: 'Vorträge anläßlich der Königsteiner Chromatographie-Tage', Herausg.: H. Aigner, ISBN3924485-00-3, Waters GmbH, Eschborn 1984, S. 1-39

246. R. Arshady, I. Ugi

"Determination of isocyano groups on polymer supports by bromination"

Talanta 31, 842-843 (1984)

247. J. Bauer, R. Herges, E. Fontain, I. Ugi

"IGOR and Computer assisted Innovation in Chemistry"

Chimia 39, 43-53 (1985)

248. R. Herges, I. Ugi

"Synthese siebengliedriger Ringe durch [s2 + p2) + p2] Cycloaddition an Homodiene" Angew. Chem. 97, 596-597 (1985); Angew. Chem. Int. Ed. Engl. 24, 594-596 (1985)

249. G. Hering, R. Stöcklein-Schneiderwind, I. Ugi, T. Pathak, N. Balgobin, J. Chattopadhyaya "Preparation and properties of chloro-N,N-dialkylamino- 2,2,2-trichlorethoxy- and chlorodialkylamine 2,2,2-trichloro-dimethyl-ethoxyphosphines and their deoxynucleoside phosphiteamidates"

Nucleosides and Nucleotides 4, 169-171 (1985)

250. K. Seeholzer, M. Baumeister, I. Ugi

"The detection of racemized amino acids by Mosher's acid."

in: 'Proc. of the Akabory Conf. 1985'

MPG, Martinsried 1985, S. 14-15

251. R. Obrecht, R. Herrmann, I. Ugi

"Isocyanide Syntheses with Phosphoroxychloride and Diisopropylamine" Synthesis 1985, 400-403 
252. R. Herrmann, G. Hübener, I. Ugi

"Chiral Sulfoxides from a-Dimethylaminoethyl ferrocene"

Tetrahedron 41, 941-947 (1985)

253. X.X. Zhou, I. Ugi, J. Chattopadhyaya

"A convenient Preparation of N-protected Nucleosides with the 2,2,2-Trichloro-t-butyloxycarbonyl (TCBOC) Group. Structural Assignment of N,N-bis TCBOC Guanoside and its Deoxy Analogue" Acta Chem. Scand. B39, 761-765 (1985)

254. I. Ugi

"Qualitative Mathematical Concepts, Models and Theories for Computer Assistance in Chemistry" J. Indian. Chem. Soc. 62, 864-868 (1985)

255. A. Gieren, C.-P. Kaerlein, T. Hübner, R. Herrmann, F. Siglmüller, I. Ugi

"Stereoselektive Synthese und Struktur von [1-(Amino-1S,2S,5R- 2-isopropyl-5-methylcyclohexyl]-

(S)-methylferrocen"

Tetrahedron 42, 427-434 (1985)

256. I. K. Ugi, J. Brandt, A.v. Scholley, S. Minker, M. Wochner, H. Schönmann, B. Straupe

"Hierarchisch strukturierte Speicherung und Ermittlung von chemischen Reaktionen"

Forschungsbericht, Information und Dokumentation, BMFT-FB-ID85-005, FIZ Karlsruhe 1985, S. 1190

257. R. Herges, I. Ugi

"Cycloadditionen von Homodienen"

Chem. Ber. 119, 829-836 (1986)

258. R. Herrmann, G. Hübener, F. Siglmüller, I. Ugi

"Chirale a-Ferrocenylalkylamine"

Liebigs Ann. Chem. 1986, 251-268

259. W.E. Hull, K. Seeholzer, M. Baumeister, I. Ugi

"A modified Synthesis of Mosher's Acid and its Use in a sensitive Stereoisomer Analysis of Amino Acid Derivates"

Tetrahedron 42, 547-552 (1986)

260. I. Ugi, H. Aigner, G. Glahsl, R. Herges, G. Hering, R. Herrmann, G. Hübener, P. Lemmen, R. Obrecht, D. Rehn, R. Schwarz, K. Seeholzer, F. Siglmüller, J. Stackebrandt, R. StöckleinSchneiderwind, S.-T. Amadou, H.v. Zychlinski

"New Reagents and Methods for the Synthesis of Peptides, b-Lactams and Oligonucleotides" in: 'Natural Produkt Chemistry', Herausg.: Atta-ur-Rahman, Springer-Verlag, Heidelberg 1986, S. 457-484

261. I. Ugi, J. Bauer, E. Fontain, J. Götz, G. Hering, P. Jacob, B. Landgraf, R. Karl, P. Lemmen, R. Schneiderwind-Stöcklein, R. Schwarz, P. Sluka, N. Balgobin, J. Chattopadhyaya, T. Pathak, X.- X. Zhou

"New Posphorylating Reagents and Protective Group Techniques for Oligonucleotide Synthesis, as well as Computer Assistance in the Design of Reagents"

Chemica Scripta 26, 205-215 (1986)

262. M. Wochner, I. Ugi

"Die Lösung kommt vom Computer"

Chem. Industrie 1986, 498-501

263. R. Herges, I. Ugi

"Improved Preparation of 2-Oxabicyclo[3.1.0]hex-3-ene (Homofuran) and 2-Thiabicyclo [3.1.0] hex3-ene (Homothiophene)"

Synthesis 1986, 1059 
264. F. Siglmüller, R. Herrmann, I. Ugi

"Chiral a-Ferrocenylalkylamines from (-)-Menthone"

Tetrahedron 1986, 5931-5940

265. I. Ugi

"Logic and Order in Stereochemistry"

Chimia 40, 340-350 (1986)

266. J.-H. Youn, R. Herrmann, I. Ugi

"Synthesis of Enantiomerically Enriched a-Sulfenylated Ketones and Aldehydes"

Synthesis 2, 159-161 (1987)

267. E. Fontain, J. Bauer, I. Ugi

"Computer Assisted Bilateral Generation of Reaction Networks from Educts and Products"

Chem. Letters 1987, 37-40

268. P. Lemmen, R. Karl, I. Ugi, N. Balgobin, J. Chattopadhyaya

"Bausteine für Oligonukleotidsynthesen mit einheitlich fragmentierbaren b-halogenierten

Schutzgruppen"

Z. Naturforschung 42 C, 442-445 (1987)

269. I. Ugi, M. Baumeister, C. Fleck, R. Herrmann, R. Obrecht, F. Siglmüller, J.-H. Youn

"Is there Hope, that Four Component Condensations will become useful for Peptide and Protein Chemistry?"

in: 'Peptides 1986', Herausg.: D. Theodoropoulos, Walter de Gruyter \& Co, Berlin 1987, S. 103-106

270. E. Fontain, J. Bauer, I. Ugi

"Computerunterstützte mechanistische Analyse der Streith-Reaktion mit dem Programm RAIN"

Z. Naturforsch. 42b, 889-891 (1987)

271. P. Lemmen, I. Ugi

"The Chiroptic Properties of the Diastereomeric 1,1'- Dimethyl-2,2'-spiro-biindones - a Comparative Study"

Chemica Scripta 27, 297-301 (1987)

272. R. Herges, I. Ugi

"Zuordnungsprobleme"

Angew. Chem. 99, 610 (1987)

Angew. Chem. Int. Ed. Engl. 26, 703 (1987)

273. H. Martin, R. Herrmann, I. Ugi

"Synthese einer chiralen Thienamycin-Vorstufe"

Z. Naturforsch. 42b, 1588-1590 (1987)

274. M. Wochner, I. Ugi

"Molecular Logic and Computer Assistance in Chemistry"

J. Mol. Structure (Theochem) 165, 229-242 (1988)

275. I. Ugi, J. Achatz, M. Baumgartner-Rupnik, B. Danzer, C. Fleck, G. Glahsl, R. Herrmann, P. Jacob, C. Kambach, R. Karl, M. Klein, B. Landgraf, P. Lemmen, H. Martin, G. Neyer, R. Obrecht, B.

Westinger

"New Reagents and Methods for the Synthesis of b-Lactams, Peptides and Oligonucleotides"

in: 'Natural Product Chemistry III', Herausg.: Atta-ur-Rahma

Springer, Heidelberg, S. 107 -133 (1988).

276. J. Bauer, E. Fontain, I. Ugi

"Computer-assisted bilateral Solution of chemical Problems and Generation of Reaction Networks" Anal. Chim. Acta 210, 123-134 (1988)

277. I. Ugi, P. Jacob, B. Landgraf, C. Rupp, P. Lemmen, U. Verfürth

"Phosphite Oxidation and the Preparation of five-membered cyclic phosphorylating Reagents"

Nucleosides and Nucleotides 7, 605-608 (1988) 
278. D. Forstmeyer, J. Bauer, E. Fontain, R. Herges, R. Herrmann, I. Ugi

"Die Umsetzung von Tropon mit einem Homopyrrol zu einem Käfigmolekül - Die computerunterstützte Entdeckung einer präzedenzlosen Reaktion von hohem Neuheitsgrad" Angew. Chem. 100, 1618-1619 (1988); Angew. Chem. Int. Ed. Engl. 27, 1558-1559 (1988)

279. J. Bauer, E. Fontain, D. Forstmeyer, I. Ugi

"Interactive Generation of organic Reactions by IGOR 2 and PC-assisted Discovery of a new Reaction"

Tetrahedron Comput. Methodol. 1, 129-132 (1988)

280. P. Lemmen, R. Baumgartner, I. Ugi, F. Ramirez

"The Deformation of the Phosphorane Skeleton as Evidence for Reorganization Pathways"

Chemica Scripta 28, 451-464 (1988)

281. M. Wochner, J. Brandt, A. v. Scholley, I. Ugi

"Chemical Similarity, Chemical Distance and its Exact Determination"

Chimia 42, 217-225 (1988)

282. I. Ugi, J. Bauer, R. Baumgartner, E. Fontain, D. Forstmeyer, S. Lohberger

"Computer Assistance in the Design of Syntheses and a new Generation of Computer Programs for the Solution of chemical Problems by molecular Logic"

Pure \& Appl. Chem. 60, 1573-1586 (1988)

283. I. Ugi, J. Bauer, E. Fontain

"Molecular Logic and the deductive Solution of chemical Problems"

Wiss. Zeitung T.H. Leuna-Merseburg, 31, 9-17 (1989)

284. J. Brandt, I. Ugi, (Herausg.)

"Computer Applications in Chemical Research and Education"

Hüthig-Verlag, Stuttgart 1989, S. 1-449

285. I. Ugi

"A global mathematical Model of Chemistry - The mathematical Contributions of James Dugundji to Chemistry"

in: 'Computer in chemical Research and Education', Herausg.: J. Brandt, I. Ugi, Hüthig Verlag, Stuttgart 1989, S. 345-366

286. B. Westinger, I. Ugi

"A new Approach to Peptide Synthesis by stereoselective Four-Component Condensation"

in: 'Chemistry of Peptides and Proteins', Vol. 4, Proceedings of the German-Soviet Peptide

Symposium 1987 Hamburg, Sept. 1987, Herausg.: W. König, Attempto-Verlag, Tübingen 1989, S. $107-110$

287. F. Siglmüller, R. Herrmann, I. Ugi

"Chirale Ferrocenylalkylamine aus dem natürlichen 'chiral Pool"'

Liebigs Ann. Chem. 1989, 623-635

288. R. Karl, P. Lemmen, I. Ugi

"Synthesis of 3'-Isocyano-3'-deoxythymidine"

Synthesis 9, 718-719 (1989).

289. I. Ugi "From Pentazole to high-dimensional Chemistry"

Proc. Estonian Acad. Sci. Chem. 38, 225-229 (1989)

290. I. Ugi, J. Bauer, E. Fontain

"Reaction Pathways on a PC"

in: 'Personal Computers for Chemists', Herausg.: J. Zupan, Elsevier, Amsterdam 1990, S.135-154

291. G. Neyer, J. Achatz, B. Danzer, I. Ugi

"The Synthesis of Carbapenem and Carbacephem Derivatives by a Combination of 4CC with the Chemistry of Oxazoles and N-Boc-carbonamides"

Heterocycles 30, 863-869 (1990) 
292. I. Ugi, M. Wochner, E. Fontain, J. Bauer, B. Gruber, R. Karl

"Chemical Similarity, Chemical Distance and Computer assisted formalized Reasoning by Analogy" in: 'Concepts and Applications of Chemical Similarity', Herausg.: M.A. Johnson, G.M. Maggiora, John Wiley \& Sons, Inc., New York 1990, S. 239-288.

293. I. Ugi, N. Bachmeier, R. Herrmann, P. Jacob, R. Karl, M. Klein, B. Landgraf, P. Lemmen, W. Richter, U. Verfürth

"Synthesis and Reactivity of five-membered cyclic phosphorylating Reagents and other Auxiliaries for the Synthesis of Oligonucleotides"

Phosphorus Sulfur \& Silicon 51/52, 57-60 (1990).

294. W. Richter, R. Karl, I. Ugi "A programmed five-membered cyclic phosphorylating Reagent for Oligonucleotide Synthesis and its Use"

Tetrahedron 46, 3167-3172 (1990)

295. J. Friedrich, W. Schubert, I. Ugi

"Computer-aided Chemical Structure-handling Techniques in Structure-Activity Relationship Systems"

in: 'Short-Term Toxicity Tests for Non-genotoxic Effects', Scope 41, IPCS Joint Symposia 8, SGOMSECY, Herausg.: P. Bourdeau, E. Somers, G.M. Richardson, J.R. Hickman, J. Wiley \& Sons, New York 1990, S. 339-345.

296. R. Arshady, I. Ugi

"Synthesis and Characterization of polymer supports carrying isocyano groups" Polymer 31, 1164-1169 (1990).

297. I. Ugi, J. Bauer, E. Fontain

"Transparent formal Methods for reducing the combinatorial Wealth of conceivable Solutions to a chemical Problem - Computer-Assisted Elucidation of complex Reaction Mechanisms"

Anal. Chim. Acta 235, 155-161 (1990).

298. I. Ugi

"Application of new formal-logical Methods to chemical Problems"

Proc. Estonian Acad. Sci Chem. 39, 193-200 (1990)

299. K. Bley, I. Ugi

"Computer-assisted Analysis of Qualitative Structure/Activity Relations in Organic Molecules"

in: 'Software Development in Chemistry 4'

Herausg.: J. Gasteiger

Springer, Heidelberg, 1990, S. 67-73.

300. W. Richter, I. Ugi

"The preparation and use of 2-Chloro-2,4-dioxo-3-methyl-tetrahydro- 1,2,3l5-thiaphosphole, a highly reactive Reagent for the Synthesis of Oligonucleotides"

Synthesis 1990, 661-663.

301. I. Ugi, B. Gruber, N. Stein, A. Demharter

"Set-valued Maps as a mathematical Basis of Computer Assistance in Stereochemistry"

J. Chem. Inf. and Comp. Sci. 30, 485-489 (1990).

302. B. Westinger, C. Fleck, M. Goebel, R. Herrmann, R. Karl, S. Lohberger, S. Reil, F. Siglmüller, I.

Ugi

"New chiral Templates for Peptide Synthesis by Four Component Condensation as well as related Methods and Reagents"

Proc. German-Soviet Peptide Symposium, 1989, (Dilizhan)

303. I. Ugi

"The Four Component Condensation, a versatile Principle in Synthesis"

Proc. Estonian Acad. Sci. Chem. 40, 1-13 (1991) 
304. S. Lehnhoff, R.M. Karl, I. Ugi

"Die Abspaltung der 2,2,2-Trichlor-tert.-butyloxy-carbonyl-Schutzgruppe mittels Zinn(II)tris[thiophenolat]" Synthesis, 4, 309-310 (1991).

305. I. Ugi, J. Bauer, K. Bley, A. Dengler, E. Fontain, M. Knauer, S. Lohberger "Computer-assisted Synthesis Design, a Status Report"

J. Mol. Structure (Theochem) 230, 73-92 (1991)

306. P. Jacob, W. Richter, I. Ugi

"2-Oxo-1,3,2-benzothiazaphosphole and 2-Oxo-1,3,2-benzoxazaphosphole Derivatives, new and versatile Phosphorylating Reagents"

Liebigs Annalen der Chemie, 1991, 519-522

307. U. Verfürth, I. Ugi

"Asymetrische Synthese chiraler Phosphorverbindungen durch destruktiv-selektive Oxidation von P(III)-Verbindungen mittels chiraler Oxaziridine"

Chem. Ber., 124, 1627-1634 (1991)

308. A. Dengler, I. Ugi

"A Central Atom Based Algorithm and Computer Program for Substructure Search" Computers \& Chemistry 15, 103-107 (1991)

309. A. Dengler, I. Ugi

"The Computer Program CABASS for Central Atom Based Substructure Search"

J. Chem. Res., (S) 162; (M) 1279-1296, 1301-1392 (1991).

310. K. Bley, J. Brandt, A. Dengler, R. Frank, I. Ugi

"Constitutional Formulas generated from Connectivity Information: the program MDRAW".

J. Chem. Res., (S) 261; (M) 2601-2689 (1919).

311. "A Novel Dieckman Type Cyclization, the Final Step of the Synthesis of a Carbacephem Derivative" Synthesis, 9, 743-744 (1991).

312. "Vernetzung wässriger Alginsäure mittels der Vierkomponenten-Kondensation unter EinschlußImmobilisierung von Enzymen", Z. Naturforsch, 46b, 1261-1265 (1991).

313. S. Lohberger, E. Fontain, I. Ugi, G. Müller, J. Lachmann

"Malonamide Derivatives as By-products of Four Component Condensation. The Computer-assisted Investigation of a Reaction Mechanism"

New Journal of Chemistry, 15, 913 - 917 (1991)

314. G. Müller, J. Lachmann, S. Lohberger, E. Fontain, I. Ugi

"Structure of an Aminomalonamide Derivative"

Acta Crystallographica, C 47, 2444 - 2446 (1991)314.

315. I. Ugi, S. Lohberger, R. Karl

"The Passerini and Ugi Reactions"

in: "Comprehensive Organic Synthesis: Selectivity for Synthetic Efficiency", Bd. 2, Kap. 4.6,

Herausg.: B. M. Trost, C. H. Heathcock, Pergamon, Oxford 1991, S. 1083 - 1109.

316. M. Goebel, I. Ugi

"O-Alkyl-1-aminoglucose-Derivate als chirale Amin-Komponenten von Peptidsynthesen mittels stereoselektiver Vierkomponenten-Kondensationen"

Synthesis, 12, 1095 - 1098( 1991), Ed. Engl. 12, 1095-1098 (1991).

317. I. Ugi, A. Dengler

"The Algebraic and Graph theoretical Completion of truncated Reaction Equations"

J. Math. Chem., 9, 1 - 10 (1992).

318. I. Ugi, J. Bauer, K. Bley, A. Dengler, A. Dietz, E. Fontain, B. Gruber, M. Knauer, K. Reitsam, N. Stein 
"Computergestütztes chemisches Rechnen, Denken und Erfinden"

Labor 2000 (Sonderheft von LaborPraxis), 170-178 (1992).

319. "2-(4 - Toluenesulphonyl )- 3 - aryl - oxaziridines as oxidizing Reagents for P(III) Compounds"

Z. Naturforsch. 47b, 887-890 (1992).

320. A. Dengler, E. Fontain, M. Knauer, N. Stein, I. Ugi

"Competing Concepts in CAOS"

Recueil 111, 262-269 (1992).

321. I. Ugi, N. Stein, M. Knauer, B. Gruber, K. Bley, R. Weidinger

"New Elements in the Representation of the Logical Structure of Chemistry by Qualitative

Mathematical Models and Corresponding Data Structures"

Top. Curr. Chem., 166, 199-233 (1993).

322. P. Lemmen, W. Richter, B. Werner, R. Karl, R. Stumpf, I. Ugi,

"Five-membered cyclic phosphorylating Reagents and related Compounds"

Synthesis, 1993, 1 - 10.

323. I. Ugi, J. Bauer, K. Bley, A. Dengler, A. Dietz, E. Fontain, B. Gruber, R. Herges, M. Knauer, K. Reitsam, N. Stein

"Computer unterstützte direkte Lösung chemischer Probleme - die Entstehungsgeschichte und gegenwärtiger Status einer neuen Disziplin der Chemie"

Angew. Chem. 105/2, 210-239 (1993); Angew. Chem. Int. Ed. Engl. 32, 201-227 (1993)

324. I. Ugi, M. Goebel, N. Bachmeier, A. Demharter, C. Fleck, R. Gleixner, S. Lehnhoff

"O-Alkyl b-Glucopyranosyl Amines as Chiral Templates for Peptide Syntheses by Stereoselective

Four Component Condensations and Related Reactions"

Proceedings, Deutsch-sowjetisches Peptidsymposium 1991.

325. I. Ugi, H. Eckert

"The Role of Isocyanides in the Synthesis of b-Lactam Antibiotics and related Compounds"

Herausg.: A. ur Rahman., "Natural Product Chemistry", Bd. 12, Elsevier, Science Publ., 1000AE Amsterdam, The Netherlands. 1992, 113-143.

326. J. Bauer, E. Fontain, I. Ugi

"IGOR and RAIN_the first mathematically based General Purpose Computer Programs for the Solution of constitutional Problems in Chemistry and their Use as Generators of constitutional Formulas"

Informal Commun. Math. Chem. (MATCH), 27, 31-47 (1992).

327. M. Strasser, I. Ugi

"The Direct Synthesis of c-AMP Derivatives and Selective 3',5'-Hydroxy Group Protection of Adenosine"

Acta Chem. Scand. 47, 125 - 130, (1993).

328. I. Ugi, N. Bachmeier, M. Klein, P. Lemmen, A. Micossi, W. Richter, M. Strasser, R. Stumpf, B. Werner

"Cyclic Phosphates Esters in Syntheses of Nucleotides, Phospholipids and related Compounds" Advances in Natural Product Chemistry, Harwood Acidemic Publishers, Edited by Atta-ur-Rahman, H.E. J. Research Institute, University of Karachi, Pakistan, ISBN 3-7186-5319-2, 91 - 120.

329. A. Demharter, I. Ugi

"The direct Synthesis of three enantiomerically pure Diastereoisomers of a

1-Ferrocenylalkylamine from l-(-)-Menthone and the up-down-Stereoisomerism of Ferrocene

Derivatives"

J. Prakt. Chem. 335, 244 - 254, (1993).

330. A. Dömling, I. Ugi

"Die Sieben-Komponenten-Reaktion" 
Angew. Chem. 105, 634-635 (1993)

Angew. Chem. Int. Ed. Engl. 32, 563-564 (1993)

331. S. König, S. Lohberger, I. Ugi

"Synthese von N-tert-Alkylglyoxylsäureamiden"

Synthesis, 12, 1233 - 1234 (1993).

332. A. Dömling, I. Ugi

"A New 5.6-Dihydro-2H-1.3-oxazine Synthesis via Asinger-type Condensation"

Tetrahedron, 49, 9495-9500 (1993).

333. W.Richter, R.Karl, M.Mayer, I.Ugi

"Trifluormethylphosphonamidite als Bausteine für die Oligonukleotidsynthese"

GDCh-Kurzreferate u. Teilnehmerverz., 483 (1993)

334. I. Ugi, B. Gruber, N. Stein

"The Models and formal Languages of Chemistry"

Proc. Estonian Acad. Sci. Chem., 43, 4, 121-136 (1994)

335. S.Hünsch, W. Richter, I. Ugi, J. Chattopadhyaya

"Synthesis and Phosphorylating Properties of 2-Chloro-2,3-dihydro-3-(methylsulfonyl)-1,3,2-

benzoxazaphosphole 2-Oxide. Derivatives with Chloro Substituents on the Benzene Ring" Liebigs Ann. Chem., 269-275 (1994).

336. I. Ugi, J. Bauer, C. Blomberger, J. Brandt, A. Dietz, E. Fontain, B. Gruber, A. v. Scholley-Pfab, A. Senff, N. Stein

"Models, Concepts, Theories, and Formal Languages in Chemistry and Their Use as a Basic for

Computer Assistance in Chemistry"

J. Chem. Inf. and Comp. Sci., 34, 3-16 (1994).

337. I. Ugi

"Pentazole"

Houben-Weyl, Methoden der Organischen Chemie, Bd. E8d, Hetarene III/ Teil 4; Herausg.: E.

Schaumann; Georg Thieme Verlag, Stuttgart, S. 796-803 (1994)

338. I. Ugi

"Mutual Perspectives in Chemistry, Mathematics and computational Reasoning"

Estonian Chemical Society, 75, 36-45 (1994); Proceedings of the Estonian Academy of Sciences;

Chemistry 44/4, 274-280, 280-287 (1995)

339. I. Ugi, A. Dömling, W. Hörl

"Multicomponent Reactions in Organic Chemistry"

Endeavour, 18/3, 115-122 (1994)

340. I. Ugi, A. Dömling, W. Hörl

"Multikomponentenreaktionen"

GIT Fachzeitschrift für das Laboratorium, 38, 430-437 (1994)

341. S. König, R. Klösel, R. Karl, I. Ugi

"N-tert-Butylglyoxylsäureamid als neues Reagens zur Peptid-Segmentverknüpfung via

Vierkomponeneten-Kondensation"

Zeitschrift für Naturforschung 49b, 1586-1995 (1994)

342. A.Dietz, B.Gruber, I.Ugi

"Algorithmische Behandlung stereochemischer Problemstellungen"

Match 31, 37-87 (1994)

343. I.Ugi, A.Dömling, B.Gruber, M.Heilingbrunner, C.Heiß, W.Hörl,

"Formale Unterstützung bei Multikomponentenreaktionen - Automatisierung der Synthesechemie" In: Software - Entwicklung in der Chemie. R.Moll (Hrsg.), Frankfurt: Gesellschaft Deutscher Chemiker, 1995, S. 113-128. (Tagungsband zu GDCh-Workshop 16.-18.11.1994). 
344. M. Klein, I. Ugi

"Chloro-N,N-dialkylamino-2,2,2-trichloro-tert-butoxy-phosphines, New Reagents in the Syntheses of Oligonucleotides "

Zeitschrift für Naturforschung 50b, 948-952 (1995)

345. S. König, I. Ugi, J. Schramm

"Facile Syntheses of C2-Symmetrical HIV-1 Protease Inhibitors"

Arch. Pharm., 328, 699-704 (1995)

346. U.Nillroth, L.Vrang, G.Ahlsén, Y.Besidsky, J.Chattopadhyaya, I.Ugi, U.H.Danielson

"The use of 5'-phosphate derivatives of nucleoside analogues as inhibitors of HIV-1 replication" Antiviral Chemistry \& Chemotherapy 6/1, 50-64 (1995)

347. A. Dömling, A.Bayler, I. Ugi

"2,5-Dihydro-4-hydroxymethyl-1,3-oxazoles by Asinger-Condensation"

Tetrahedron, 51/3, 755-760 (1995)

348. S. Lehnhoff, I. Ugi

"Synthesis of 1,5-substituted Tetrazoles from secondary Thioamides"

Heterocycles 40/2, 801-808 (1995)

349. K. Kehagia, A. Dömling, I. Ugi

"The Formation of ß-Lactam Derivatives and a C3-Symmetrical Heterocycle from 5, 6-Dihydro-2H-1, 3-oxazines"

Tetrahedron 51/1, 139-144 (1995)

350. K. Kehagia, A. Dömling, I. Ugi, W. Hiller, J. Riede

"New synthesis and structure Determination of 13-Aza-4,4,8,8,12,12-hexamethyl-2,6,10trioxatricyclo[7,3,1 05,13]tridecane"

Zeitschrift für Naturforschung 50b, 667-670 (1995)

351. K.Kehagia, I.Ugi

"The Synthesis of 4-Acetoxy-azetidinones as Key Intermediates for ß-Lactams"

Tetrahedron 51/35, 9523-9530 (1995)

352. N.Müller, A. Senff, S. Reichelt, I.Ugi

"Topological Specification of Ensembles of Molecules as a Basis of Stereochemical Regards" Theochem 336, 209-225 (1995)

353. R. M. Karl, R. Klösel, S. König, S. Lehnhoff, I. Ugi

"1,1-Dianisyl-2,2,2-trichloroethyl Ethers - A New Protecting for the Hydroxyl Group"

Tetrahedron 51/13, 3759-3766 (1995)

354. N.Puri, S.Hünsch, C.Sund, I.Ugi, I.Chattopadhyaya

"The Synthesis and Reactivity of New 2-(N,N-Diisopropylamino)-3Methylsulfonyl-1,3,2-

Benzoxazaphospholes. The Utility of the 5-Chloro analog in the One-Pot Synthesis of Oligothiophosphates: [ApsppA, ApsppA, ppp5'A2'ps5'A, m7GpsppA, Apspppp, Apspp]"

Tetrahedron 51/10, 2991-3014 (1995)

355. S.Lehnhoff, M.Goebel, R.M.Karl, R.Klösel, I.Ugi

"Stereoselektive Synthesen von Peptidderivaten mit 2-Acetamido-3,4,6-tri-O-acetyl-1-amino-2desoxy-b-D-glucopyranose durch Vierkomponentenkondensation"

Angew. Chemie, 107/10, 1208-1211 (1995), Angew. Chem. Int. Ed. Engl. 34/10, 1104-1107 (1995)

356. A.Dömling, M.Starnecker, I.Ugi

"b-Lactam-Nucleosid-Chimäre"

Angew. Chemie, 107/20, 2465-2467 (1995), Angew. Chem. Int. Ed. Engl. 34, 2238-2239 (1995)

357. I.Ugi, A.Dömling, M.Goebel, B.Gruber, M.Heilingbrunner, C.Heiß, W.Hörl

"Multi Component Reactions (MCR) For The Generation Of Molecular Diversity"

Conference (Poster) "Cambridge Healthtech Institute" La Jolla 23.-25.Jan. 1995 
358. I. Ugi,

"Fast and permanent Changes in Preparative and Pharmaceutical Chemistry through Multi

Component Reactions and their 'Libraries"'

Proc. Estonian Acad. Sci. Chem. 44/4, 237-273 (1995)

359. I.Ugi, A.Dömling, M.Goebel, W.Hörl, K.Kehagia, S.Lehnhoff, M.Starnecker

"Flerkomponentsreaktioner ger nya läkemedel"

Kemisk Tidskrift, 4, 50-53 (1995)

360. H.Eckert, A.Nestl, I.Ugi

"t-Butyl Isocyanide"

Encyclopedia of Reagents for Organic Synthesis, Ed. L.A. Paquette; John Wiley, 2, 893 (1995) 1995

361. H.Eckert, A.Nestl, I.Ugi

"Methyl Isocyanide"

Encyclopedia of Reagents for Organic Synthesis, Ed. L.A. Paquette; John Wiley, 5, 3519 (1995)

362. H.Eckert, A.Nestl, I.Ugi

"Phenyl Isocyanide"

Encyclopedia of Reagents for Organic Synthesis, Ed. L.A. Paquette; John Wiley, 6, 3991 (1995)

363. H.Eckert, A.Nestl, I.Ugi

"o-Tolyl Isocyanide"

Encyclopedia of Reagents for Organic Synthesis, Ed. L.A. Paquette; John Wiley, 7, 4964 (1995)

364. M.Goebel, I.Ugi

"Beyond Peptide and Nucleic Acid Combinatorial Libraries-Applying Unions of Multicomponent Reactions towards the Generation of Carbohydrate Combinatorial Libraries"

Tetrahedron Letters, 36, 34, 6043-6046 (1995)

365. M.Weber, I.Ugi

"Common Pathways to 1,3,2-Thiazaphospholidin-4-ones"

Liebigs Ann.Chem., 1555-1559 (1995)

366. A.Dömling, K.Kehagia, I.Ugi

"Employment of a Steroidal Aldehyde in a New Synthesis of ß-Lactam Derivatives"

Tetrahedron 51/35, 9519-9522 (1995)

367. M.Mayer, I.Ugi, W.Richter

"Studies on Trifluoromethylphosphonamidite Analogues as Building Blocks in Oligonucleotide Synthesis"

Tetrahedron Letters 36/12, 2047-2050 (1995)

368. A.Senff, S.Reichelt, N.Müller, I.Ugi

"Topology and Group Theory-Tools for Determinating the Stereochemistry of Molecules"

Conference (Poster) Math/CHEM/COMP Dubrovnic/Croatia 24.6.-1.7. (1995)

369. A.Demharter, W.Hörl, E.Herdtweck, I.Ugi

"Synthese chiraler 1.1'-Iminodicarbonsäure-Derivate aus a-Aminosäuren, Aldehyden, Isocyaniden und Alkoholen durch eine diastereoselektive Fünfzentren-Vierkomponenten-Reaktion"

Angew. Chemie 108/2, 185-187 (1996), Angew. Chem. Int. Ed. Engl. 35/2, 173-175 (1996)

370. R.M.Karl, W.Richter, R.Klösel, M.Mayer, I.Ugi

"The 1,1-Dianisyl-2,2,2-Trichloroethyl Moiety as a New Protective Group for the Synthesis of

Dinucleoside Trifluoromethylphosphonates"

Nucleosides \& Nucleotides 15, 379-386 (1996)

371. I.Ugi, M.Goebel, B.Gruber, M.Heilingbrunner, C.Heiß, W.Hörl, O.Kern, M.Starnecker, A. Dömling "Molecular Libraries in Liquid Phase via Ugi-MCR"

Research on Chemical Intermediates, 22. 625 - 644 (1996) 
372. I.Ugi, A.Demharter, W.Hörl, T.Schmid

"Ugi Reactions with Trifunctional Amino Acids, Aldehydes, Isocyanides and Alcohols"

Tetrahedron, 52/35, 11657-11664 (1996)

373. S.Reichelt, A.Reichelt, N.Müller, I.Ugi

"Topology and Group Theory-Tools for Determinating the Stereochemistry of Molecules"

Croatica Chemica Acta, 69/3, 813-825 (1996)

374. M.Goebel, H.-G. Nothofer, G.Roß, I.Ugi

"A Facile Synthesis of Per-O-alkylated Glycono-d-lactones from Per-O-alkylated Glycopyranosides and a Novel Ring Contraction"

Tetrahedron, 53/9, 3123-3134 (1997)

375. I. Ugi, M. Heilingbrunner, B. Gruber

"Heuristik, Genetischer Algorithmus und andere Zufälligkeiten in der Computerchemie"

Chimia, 51-12, 39-44 (1997)

376. I.Ugi

"The Multicomponent Reactions and their Libraries - Perspectives of Progress in Organic Chemistry and its Application"

Acta Polytechnica Scandinavica, 244, 64-65 (1997), Proceedings of the Symposium on

Crystallization and Precipitation 12-14 May 1997, Lappeenranta, Finland (1997)

377. I. Ugi, M. Heilingbrunner, B. Gruber

"Über die Computerchemie"

Nachr. aus Chemie, Techn. und Lab., 45/5, 507-509 (1997)

378. H.Bock, I.Ugi

"MCR II: Stereoselective Synthesis of 1(S)-Camphor-2-cis-methylidene-isocyanide and its

Application in Passerini-and Ugi-Reaction"

Journal für Praktische Chemie, 339, 385-389 (1997)

379. I.Ugi, A.Dömling, B.Gruber, M.Almstetter

"Multicomponent Reactions and Their Libraries - A New Approach to Preparative Organic

Chemistry"

Croatica Chemica Acta, 70/2,631-647 (1997)

380. I.Ugi

"MCR I: Perspektiven von Multikomponentenreaktionen und ihren Bibliotheken"

Journal für Praktische Chemie, 339, 499-516 (1997)

381. J.Chattopadhyaya, A.Dömling, K.Lorenz, W.Richter, I.Ugi, B.Werner

"MCR III. Multicomponent Reactions and their Libraries, a New Type of Organic Chemistry of the Isocyanides and Phosphorus Derivatives"

Nucleosides and Nucleotides, 16/5-6, 843-848 (1997)

382. I.Ugi, T.Schmid

"MCR VIII: Aziridine-Derivateds via Ugi-Reactions"

Journal für Praktische Chemie, 339, 652-655 (1997)

383. I.Ugi, M.Almstetter, B.Gruber, A.Dömling

"MCR X. Important Aspects for Automating Preparative MCR-Chemistry"

Springer Verlag, Berlin, 1998, S. 184-189, Dechema-Tagung, 23.-25.2.1997

384. I.Ugi, M.Almstetter, B.Gruber, M.Heilingbrunner

"MCR XII. Efficient Development of New Drugs by Online-Optimization of Molecular Libraries"

Springer Verlag, Berlin, 1998, S. 190-194, Dechema-Tagung, 23.-25.2.1997

385. A.Dömling, E.Herdtweck, I.Ugi

"MCR V. The Seven Component Reaction"

Acta Chemica Scandinavica, 52, 107-113 (1998) 
386. I.Ugi, W.Hörl. T.Schmid, C.Hanusch-Kompa, E.Herdtweck

"MCR VI: Chiral 2,6-Piperazindiones via Ugi Reactions with a-Amino Acids, Carbonyl Compounds, Isocyanides and Alcohols"

Heterocycles, 47/2, 965-975 (1998)

387. I.Ugi, M. Almstetter, H. Bock, A. Dömling, B. Ebert, B.Gruber, K. Kehagia-Drikos, C. HanuschKompa, S. Heck, K. Lorenz, S. Papathoma, T. Schmid, B. Werner, A. von Zychlinski

"MCR XIV. The History, Presence and Future of the Multicomponent Reactions - their Versatile Multidisciplinary Facets of Preparative and Theoretical Chemistry"

Workshop, Rzeszow, 28.-30. Sept. 1997 University of Technology, Rzeszow / Technical University, Munich, 1998

388. Z. Hippe, I.Ugi (Eds.)

"MultiComponent Reactions \& Combinatorial Chemistry - Proceedings of the German-Polish

Workshop, Rzeszow, 28.-30. Sept. 1997"

University of Technology, Rzeszow / Technical University, Munich, 1998

389. I.Ugi

"My first 65 Years"

in: Multikomponenten-Reaktionen, H. Eckert (Hrsg.), Ugi-Symposium 22. September 1995, 30-54,

Techn. Universität, München 1997

390. C.Hanusch-Kompa, I.Ugi

"MCR XIII. Synthesis of g-Lactams as part of a Multi-Ring-System via Ugi-4-Centre-3-ComponentReaction"

Tetrahedron Letters, 39, 2725-2728 (1998)

391. B.M.Ebert, I.K. Ugi

"MCR VII: Dibenso-1,5-diazocine-2,6-dione, 2-Iminoindoline-3-one and N-(Carbamoylmethyl)aminobenzoic Acid Ester from Aminobenzoic Acid by Multicomponent Reactions"

Tetrahedron, 54, 11887-11898 (1998)

392. I. Ugi

"MCR XXIII. The highly variable multidisciplinary Preparative and Theoretical Possibilities of the

Ugi Multicomponent Reactions in the Past, Now and in the Future"

Proceedings of the Estonian Academy of Sciences, 47/3, 107-127 (1998)

393. I. Ugi

"The Progress in the Development of Multicomponent Reaction (MCR) and their Libraries in the last Century, Now and in the Future"

National Science Seminar Complex, Astra Symposium, 17.-19.9.98, 1-3 (1998)

394. I. Ugi

"MCR XXI: Ugi Multikomponentsed Reaktsioonid Eile, Täna Ja Homme, Nende Preparatiivse Ja

Teoreetilise Keemia Mitmekülgsed Multidistsiplinaarsed Võimalused"

Techn. Univ., München, Estn. Akademie, Tallinn, 1998

395. I. Ugi, M. Almstetter, H. Bock, A. Dömling, B. Ebert, B. Gruber, C. Hanusch-Kompa, S. Heck, K. Kehagia-Drikos, K. Lorenz, S. Papathoma, R. Raditschnig, T. Schmid, B. Werner, A. von Zychlinski "MCR XVII: Three Types of MCR\&rsquos and the Libraries - their Chemistry of Natural Events and the Preparative Chemistry"

Croatica Chemica Acta, 71/3, 527-547 (1998)

396. I. Ugi, M. Almstetter, A. Dömling, B. Ebert, B. Gruber, W. Hörl, M. Starnecker, O. Kern "Multicomponent Reactions improve the Libraries of Peptides and Small Organic Molecules"

24th European Peptide Symposium Proceedings Book, Edinburgh, 8.-13.09.1996 in: Peptides 1996, Robert Ramage and Roger Epton 1998, 135 - 138

397. I. Ugi

"Wandel tut not" 
in: Quo vadis Chemie - Gegenwart und Zukunft des Chemiestudiums in Deutschland zusammengestellt vom GDCh-Jungchemikerforum, Regionalgruppe Bielefeld, Gesellschaft Deutscher Chemiker e.V., Frankfurt 1998, S. 58-59

398. A.v. Zychlinski, I.Ugi

"MCR IX: A New and Easy Way for the Preparation of Piperazine-2-keto-3-carboxamides" Heterocycles, 49, 29-32 (1998)

399. T. Lindhorst, H. Bock, I. Ugi

"A New Class of Convertible Isocyanides in the Ugi Four-Component Reaction"

Tetrahedron, 55, 7411-7420 (1999)

400. I. Ugi, A. Dömling, B. Ebert

"Combinatorial Chemistry of Multicomponent Reactions"

in: Combinatorial Chemistry Herausg.: G. Jung, Wiley-VCH, Weinheim, 2000, S.125-165

401. A. Dömling, W. Richter, I. Ugi

"Combinatorial Generation of Nucleobase Libraries by MCR"

Nucleosides \& Nucleotides, 16 (5-7), 1753-56 (1997)

402. I. Ugi, A. Dömling, B. Werner

"The modern chemistry of the isocyanides, multicomponent reactions and their libraries"

Res. Adv. in Organic Chem., 1, 91-106 (2000)

403. I. Ugi, A. Dömling, B. Werner

"Since 1995 the New Chemistry of Multicomponent Reactions and Their Libraries, Including Their Heterocyclic Chemistry"

J. Heterocyclic Chem., 37, 647-658 (2000)

404. A. Dömling, I. Ugi

"Multicomponent Reactions with Isocyanides"

Angew. Chem. Int. Ed., 39, 3168-3210 (2000)

405. I. Ugi, A. Dömling

"Multi-component reactions (MCRs) of isocyanides and their chemical libraries"

in: "Combinatorial Chemistry" H. Fenniri (Hrsg.), a.d.R.: "Practical Approach", Oxford University

Press, Oxford 2000, p. 287-302

406. I. Ugi, Birgit Werner, Alexander Dömling.

" Multicomponent reactions of isocyanides and the formation of heterocycles "

Targets in Heterocyclic Systems 4, 1-23 (2000).

407. I. Ugi, A. Dömling, B. Werner

"The one-pot Syntheses of alpha-Aminoacid and Peptide Derivatives by MultiComponent Reactions of Isocyanides"

in: Houben-Weyl Methods of Organic Chemistry "Synthesis of Peptides and Peptidomimetics", Herausg.: L. Moroder, Thieme, Stuttgart, New York, 878-889 (2000).

408. I. Ugi, A. Dömling

"Formation of Heterocyclic Compounds by MultiComponent Reactions (MCRs)"

in: "Targets in Heterocyclic Systems"; Herausg.: O. A. Attanasi, D. Spinelli, Italian Society of

Chemistry, Rom, Vol. 4, (2000).

409. I. Ugi, A. Dömling, Oliver Kern

" Liquid and solid phase syntheses by multi component reactions."

Innovation and Perspectives in Solid Phase Synthesis \& Combinatorial Libraries: Peptides, Proteins and Nucleic Acids--Small Molecule Organic Chemistry Diversity, Collected Papers, International Symposium, 6th, York, United Kingdom, Aug. 31-Sept. 4, 1999 (2001), Meeting Date 1999, 189-194. 410. I. Ugi

"Recent progress in the chemistry of multicomponent reactions."

Pure and Applied Chemistry 73, 187-191 (2001). 
411. B. Ebert, W. Hörl, I. Ugi

MCR XXIV: "Formation of 1,1'-Iminocarboxylic acid derivatives, 2,6-Diketo-piperazine- and Dibenzodiazocine-2,6-dione by Variations of Higher Multicomponent Reactions"

Chemosphere, 43, 75-81 (2001) - dedicated to Prof. Madeleine Joullie.

412. G. Ross, I. Ugi

" Stereoselective syntheses of $\alpha$-amino acid and peptide derivatives by the U-4CR of 5-desoxy-5thio-D-xylopyranosylamine."

Canadian Journal of Chemistry 79, 1934-1939 (2001).

413. D. Janezic, M. Hodoscek, I. Ugi

"The simultaneous $\alpha$-addition of a cation and an anion onto an isocyanide."

Internet Electronic Journal of Molecular Design 1, 293-299 (2002).

414. G. Ross, E. Herdtweck, I. Ugi

" Stereoselective U-4CRs with 1-amino-5-desoxy-5-thio-2,3,4-O-isobutanoyl- $\beta$-D-xylopyranose-an effective and selectively removable chiral auxiliary."

Tetrahedron 58, 6127-6133 (2002).

415. Drabik, Julia Maria; Achatz, Josef; I. Ugi

" Stereoselective one-pot synthesis of $\alpha$-amino acid derivatives by four component reactions with 1amino-carbohydrates and isocyanides."

Proceedings of the Estonian Academy of Sciences, Chemistry 51, 156-168 (2002).

416. A.O.L. Manguro, P. Lemmen, I. Ugi, W. Kraus.

" Flavonol glycosides of Maesa lanceolata leaves."

Natural Product Sciences 8, 77-82 (2002).

417. A.O.L. Manguro, I. Ugi, R. Hermann, P. Lemmen, Peter.

" Flavonol and drimane-type sesquiterpene glycosides of Warburgia stuhlmannii leaves."

Phytochemistry (Elsevier) 63, 497-502 (2003).

418. I. Ugi, G. Ross, C. Burdack.

" The chemical progress of multicomponent reactions."

Advanced Macromolecular and Supramolecular Materials and Processes 239-250 (2003).

419. A.O.L. Manguro, J.O. Midiwo, W. Kraus, I. Ugi.

" Benzoquinone derivatives of Myrsine africana and Maesa lanceolata."

Phytochemistry (Elsevier) 64, 855-862 (2003).

420. A.O.L. Manguro, I. Ugi, P. Lemmen, R. Hermann.

" Flavonol glycosides of Warburgia ugandensis leaves."

Phytochemistry (Elsevier) 64, 891-896 (2003).

421. A.O.L. Manguro, I. Ugi, P. Lemen.

" Further flavonol glycosides of Embelia schimperi leaves."

Bulletin of the Chemical Society of Ethiopia 18, $51-57$ (2004).

422. A.O.L. Manguro, I. Ugi, P. Lemmen.

" Flavonol glycosides from the leaves of Embelia keniensis."

Journal of the Chinese Chemical Society (Taipei, Taiwan) 52, 201-208 (2005). 